- Strong deviation of alcohol mixtures from the ideality

- formation of nanophases of alcohol molecules gathered in aggregates from hydrogen bonds leading to the spatial heterogeneity

- The aggregates of short alcohol are found uncorrelated at the long range correlations which is related to an absence of the prepeak at low Q in the total structure factor

- Microstructure and favorable $\pi-\mathrm{OH}$ interactions 


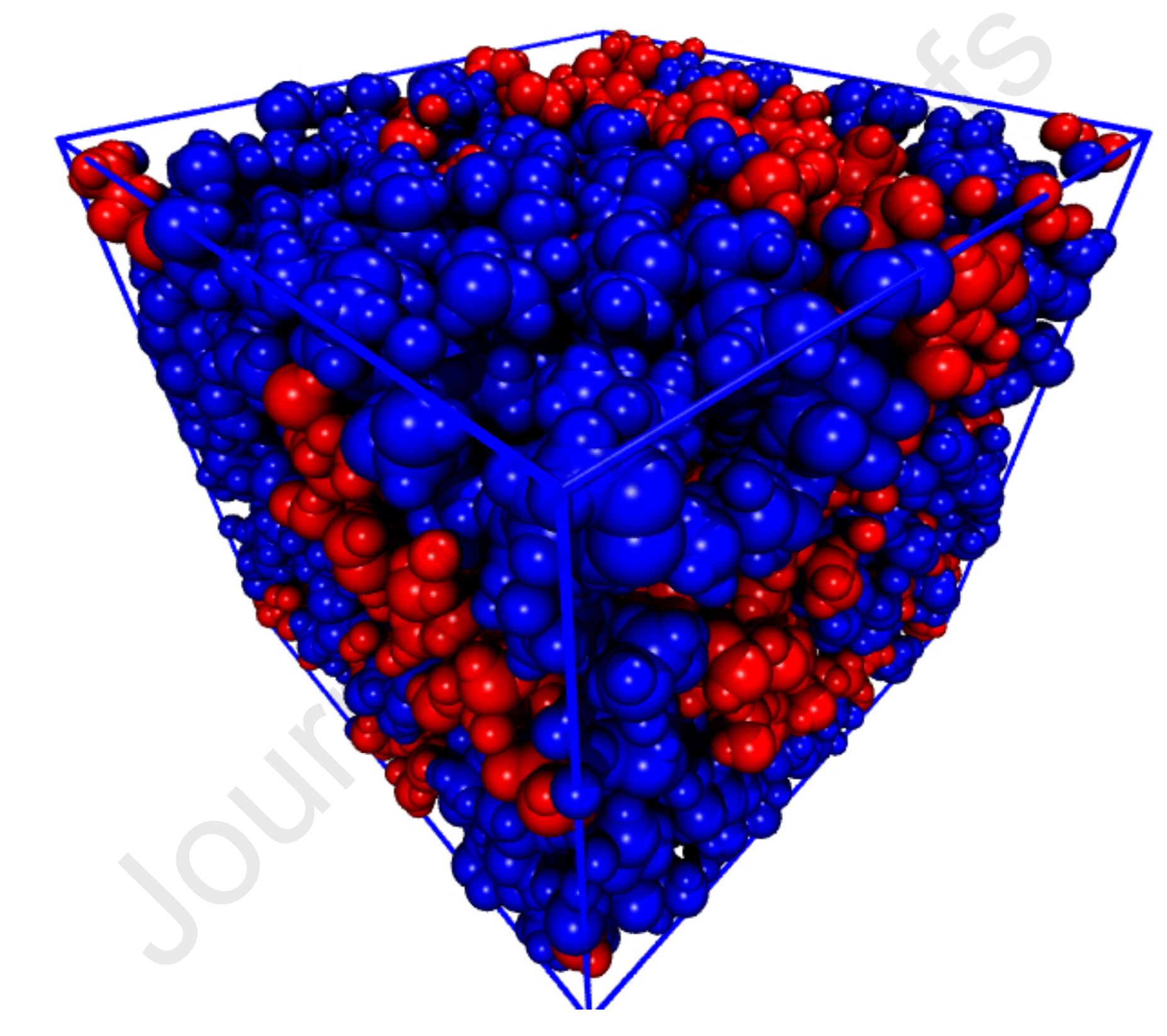

\section{Graphical Abstact (pictogram) (for review)}

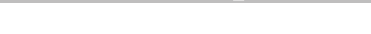

,

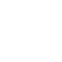




\title{
Effect of the alkyl chain length on the non-ideality and the microstructure of alcohol binary mixtures.
}

\author{
I. Essafri ${ }^{\mathrm{a}, * *}$, A. Ghoufia, \\ ${ }^{a}$ Institut de Physique de Rennes, IPR, CNRS-Université de Rennes 1, UMR CNRS 6251, 35042 Rennes, France
}

\begin{abstract}
In this study the microstructure of alcohol binary mixtures (toluene and cyclohexane) is investigated from molecular dynamics simulations. In case of cyclohexane mixtures, we show that the strong deviation from the ideality is the result of the formation of nanophases of alcohol molecules gatheblack in aggregates from hydrogen bonds leading to the spatial heterogeneity. Nanophases disappear as the alkyl chain size increases because the hydrophobic interactions counteracts the hydrogen bonds ones. The aggregates of short alcohol are found uncorrelated at the long range correlations which is related to an absence of the prepeak at low Q in the total structure factor. From toluene similar trends are observed with a lesser extend given the favorable $\pi$-OH interactions.
\end{abstract}

(C) 2011 Published by Elsevier Ltd.

Keywords: microstructure, binary alcohol mixture, spatial heterogeneity, molecular dynamics simulation

\section{Introduction}

Thermodynamical properties of binary mixtures are crucial to design and optimize the chemical industry $[1,2,3]$. These properties are important not only for a fundamental understanding of mixing processes, but also for many practical problems during the design of products, processes and industrial equipment. It is possible to pblackict the thermodynamic properties of binary systems from the properties of pure components, but in many cases such approaches are very inaccurate due to the complex interactions between components of the mixture such as hydrogen bonds, molecular association, dipole-dipole or induced dipolar interactions. As a consequence, deviations from an ideal behavior of thermodynamic mixture properties leads to a non-ideal mixture. These deviations can be captublack from the excess properties and are related to the unlike molecular intermolecular interactions between the components forming binary systems leading to specific spatial organization at the nanoscale [4,5]. Polar/apolar mixtures such as alcohol/alkane, alcohol/toluene, etc. represent a class of binary mixtures widely used in chemical industry with strong deviations from the ideality that explains that many works were devoted to the understanding of their non-ideality since 1970's.

It was then evidenced that the non-ideality of alcohol/alkane mixtures was the consequence of the balance between both hydrophobic and hydrophilic moiety $[6,7,8,9,10,11,12]$. Regarding to the propyl/alcohol mixture its nonideality behavior was correlated to the degree of self-association of the alcohol molecules [13] and to the structural changes [14]. According to Ness and fletcher, the anomalous behavior of the alcohol/alkane mixtures was related

\footnotetext{
*Corresponding author: aziz.ghoufi@univ-rennes1.fr

${ }^{* *}$ Corresponding author: ilham.essafri@gmail.com
} 
to i) the formation of clusters between molecules through their hydrogen bonds and ii) the formation of complexes between alcohols and non-polar molecules $[15,16]$. Tanaka et al. have shown that excess thermodynamic properties of ethanol/toluene mixtures and other aromatic molecules are the result of the $\mathrm{OH}-\pi$ interaction between the ethanol and the aromatic molecule [17]. That was recently corroborated from a numerical study based on molecular simulation [4] and from Hwa and Ziegler that studied ethanol/toluene mixtures [18]. Later, Morávková et al interpreted the sign of the excess properties of the binary ethanol/toluene mixture as the result of the breaking of hydrogen bonding network [19].

Molecular understanding of the non-ideality can be performed from atomistic simulation that is a powerful approach to reveal the molecular structure of the binary systems. Recently the non-ideality of methanol/toluene and methanol/cyclohexane binary liquid mixtures and the connection with the structure at the nanoscale have been undertaken by means of molecular dynamics simulations [4]. The toluene was consideblack given its high hydrophobic character and its aromatic cycle at the origin of the miscibility of organic solvents in the alcohols. In the case of toluene, this non-ideality (positive excess density) and the miscibility have been ascribed with the specific interactions between toluene and methanol $(\mathrm{MeOH})$ leading to a breaking in the hydrogen bonding network involving clusters of different sizes and the spatial heterogeneity. The immiscibility and the non-ideality (negative excess density) of $\mathrm{MeOH} / \mathrm{CHX}$ mixtures were the result of the unfavorable interactions between $\mathrm{CHX}$ and $\mathrm{MeOH}$ leading to a selforganizing of $\mathrm{MeOH}$ molecules to form nanophases at the origin of the structural heterogeneity. Spatial/structural heterogeneity is related to the presence of different phases at the nanoscale; nanophase inducing a microstructure. Therefore, the terms microstructure and spatial/structural heterogeneity will be used equally.

While methanol and ethanol have been strongly investigated, alcohols with higher alkyl chain were less studied. However, to well apprehend the microscopic origin of the non ideality the dependence of effect of the alkyl chain length has to be undertaken. Indeed, alkyl chain length could strongly influence size of nanophases and then impact the degree of the non-ideality. Patil et al. have highlighted that the increase of chain length of acrylic esters from methyl- to butyl-acrylate involves a decrease in the excess molar volume function [20]. More recently, Satheesh et al. studied mixtures composed of isoamyl alcohol (IAA) and monocyclic aromatic, they showed that the non-ideality behavior of IAA and nitrobenzene binary liquid could be resulted from physical, chemical and structural molecular parameters, in which the $\mathrm{OH}-\pi$ interactions appears to be amongst the dominated interactions in such mixtures [21]. Li et al. have explained the deviations from ideality in 1-butanol/ethylcyclohexane binary mixture as the modification of the hydrogen bonding network of 1-butanol [22].

These studies evidenced then the role of the alkyl chain length on the deviation from the ideality of alcohols mixtures. As previously mentioned the non-ideality of mixture of simple alcohol such as methanol is intimately connected to the spatial heterogeneity induced by the formation of nanophases and the dilution of the hydrogen bonding network [4]. It would be then fundamentally relevant to explore the structure of alcohol mixtures with higher alkyl chain and to characterize the degree of spatial heterogeneity and its connection with the deviation from the ideality. In this work, we aim to extend our understanding of the interplay between the microstructure and the nonideality behavior of alcohol with the increase in alcohol alkyl chain length. To do so, equilibrium molecular dynamics simulations of mixtures of toluene (TOL) and cyclohexane (CHX) with ethanol (EtOH), propanol $(\mathrm{PrOH})$, butanol $(\mathrm{BuOH})$ and pentanol $(\mathrm{PtOH})$ are carried out. Indeed, toluene molecules are capable to induce strong interactions with alcohol molecules contrary to cyclohexane that allows us to investigate the role of the $\mathrm{OH}-\pi$ interactions. Let us note that these alcohols are fully miscible in both CHX and TOL solvents at whole range concentration $[8,9,23,24]$.

\section{Simulation Details}

The all-atom optimized potentials for liquid simulations force field (OPLS-AA) [25] were used to describe TOL, $\mathrm{CHX}, \mathrm{EtOH}, \mathrm{PrOH}, \mathrm{BuOH}$ and $\mathrm{PtOH}$ molecules. Molecular dynamics (MD) simulations were carried out using D1_Poly software package [26]. Non-bonding interactions are accounted through the Lennard-Jones (LJ) potential and the Coulombic interactions. The LJ parameters for unlike interactions were calculated using the Lorentz-Berthelot mixing rules. Electrostatic interactions were calculated from the Ewald sum using a convergence parameter of $1 \mathrm{E}^{-6}$. Temperature and pressure were fixed at $\mathrm{T}=298 \mathrm{~K}$ and $\mathrm{p}=1$ atm and were kept constant through the Berendsen thermostat and barostat with relaxation times of 0.1 and $0.5 \mathrm{ps}$, respectively. The integration of the equations of motion was performed using the Verlet integration scheme. The timestep is $1 \mathrm{fs}$ and configurations were saved every $100 \mathrm{fs}$ in each production run of $10 \mathrm{~ns}$ after an equilibration of $10 \mathrm{~ns}$. To be in line with previous study [4] number of molecules 
in each mixture is 500. Let us note that the thermal and the mechanical equilibria are found reached. MD simulations were performed for 11 different mole fractions from 0.0 to 1.0. Molecules have been randomly inserted in a cubic box of length of $50 \AA$. The final box lengths are provided in Table S1 of the Supporting Information. Calculations of partial structure factor, cluster size distributions and pairwise interactions are detailed in the supporting information.

\section{Results and discussion}

In Figure 1a we report the simulated, the experimental and the ideal densities of EtOH/CHX and EtOH/TOL binary mixtures. First, a good agreement between calculated and experimental densities is found what validates the so-used force field and crossed interactions. Figure S1a of the Supporting Information shows the time evolution of the density for the pure CHX and TOL. As shown in Figure S1a the density is well converged and the average uncertainty about the density are found around $15 \mathrm{~kg} / \mathrm{m}^{3}$ that involves equilibrated systems.For both EtOH/CHX and EtOH/TOL mixtures Figure 1a exhibits strong deviations from ideal density calculated from the pure component densities such as $\rho^{\text {ideal }}=x_{\mathrm{EtOH}} \rho_{E t O H}+\left(1-x_{\mathrm{EtOH}}\right) \rho_{T O L o r C H X}$. The non-ideality can be quantified from the calculation of the excess density corresponding to the difference between the simulated and the ideal densities. We report in Figure $1 \mathrm{~b}$ the excess density of both $\mathrm{EtOH} / \mathrm{CHX}$ and $\mathrm{EtOH} / \mathrm{TOL}$ binary mixtures as a function of $\mathrm{x}_{\mathrm{EtOH}}$. As shown in Figure $1 \mathrm{~b}$ the excess density of $\mathrm{EtOH} / \mathrm{TOL}$ mixture is rather positive contrary to the $\mathrm{EtOH} / \mathrm{CHX}$ mixtures that presents a negative contribution that is in fair agreement with experiment. However the two mixtures show a similar extremum in terms of absolute value around $x_{\mathrm{EtOH}}=0.6$, a maximum for $\mathrm{EtOH} / \mathrm{TOL}$ and a minimum for EtOH/CHX. Regarding to the $\mathrm{EtOH} / \mathrm{CHX}$ mixture the excess density is first positive from $x_{\mathrm{EtOH}}=0.0$ to $x_{\mathrm{EtOH}}=0.2$ and becomes negative from $x_{\mathrm{EtOH}}=0.2$ to $x_{\mathrm{EtOH}}=0.9$. To examine the deviation of the non-ideality as a function of the alkyl chain length we report in Figure $1 \mathrm{c}$ the density of $\mathrm{PtOH} / \mathrm{CHX}$ and $\mathrm{PtOH} / \mathrm{TOL}$ as a function of $x_{\mathrm{PtOH}}$. Contrary to EtOH the deviation from the ideality is less pronounced that $\mathrm{EtOH}$ what is corroborated from the calculation of the excess density reported in Figure 1d. Interestingly, a good concordance between calculated and experimental excess density was found what validates the so-used models. From CHX a minimum of $-5.0 \mathrm{~kg} \mathrm{~m}^{-3}$ is observed at $x_{\mathrm{PtOH}}=0.5$ against $-10.0 \mathrm{~kg} \mathrm{~m}^{-3}$ in case of EtOH. Interestingly, the non-ideal character is also less pronounced in $\mathrm{PtOH} / \mathrm{TOL}$ mixture than $\mathrm{PtOH} / \mathrm{CHX}$. The effect of alkyl chain on the non-ideality behavior is confirmed in Figures S2a,b,d,e of the supporting information where density and the excess density of propanol and butanol mixtures are reported. As shown in Figures S2a,b,d,e the deviation with respect to an ideal mixture gradually decreases from $\mathrm{EtOH}$ to $\mathrm{PtOH}$.

Interestingly, from the study of $\mathrm{MeOH}$ mixtures, it has been recently evidenced that these deviations were the results of the change in the structural topology leading to a spatial heterogeneity as a consequence of the difference in the interactions between both components of the binary liquid mixtures [4]. Indeed, the positive excess density was ascribed with the specific interactions between toluene and methanol leading to a breaking in the hydrogen bonding network involving clusters of different sizes and the spatial heterogeneity. The negative excess density of $\mathrm{MeOH} / \mathrm{CHX}$ mixtures were the result of the unfavorable interactions between $\mathrm{CHX}$ and MeOH leading to a self-organizing of $\mathrm{CHX}$ molecules to form hydrophobic nanophases at the origin of the spatial heterogeneity. Therefore the increases in alkyl chain length have to increase the hydrophobic interactions between aprotic solvent from their alkyl chain involving thus a higher dilution of the alcohol. Figure 1 and Figures S2a,b,d,e confirm this behavior. That is bears out from Table 1 where the maximum of excess density as a function of the mixture is reported. The positive and the negative excess density can be then understood in terms of molecular interactions and spatial heterogeneity at the nanoscale $[27,28,29,4]$.

The spatial heterogeneity can be quantified from the calculation of the heterogeneity order parameter (HOP) $[30,31]$ obtained from

$$
H O P=\frac{1}{N_{s}} \sum_{i=1}^{N_{s}} \sum_{j=1}^{N_{s}} \exp \left(-\frac{r_{i j}^{2}}{2 \sigma^{2}}\right)
$$

such that $N_{s}$ is the total number of sites in the system that represents the centres of mass of molecules, $\mathrm{r}_{i j}$ is the distance between sites $i$ and $j$, and $\sigma=\frac{L}{N_{s}^{\frac{1}{3}}}, L$ is the length of the cubic simulation box. The value of HOP increases with the expansion of the spatial heterogeneity because a tighter packing of sites results in a smaller $\mathbf{r}_{i j}$, which leads 

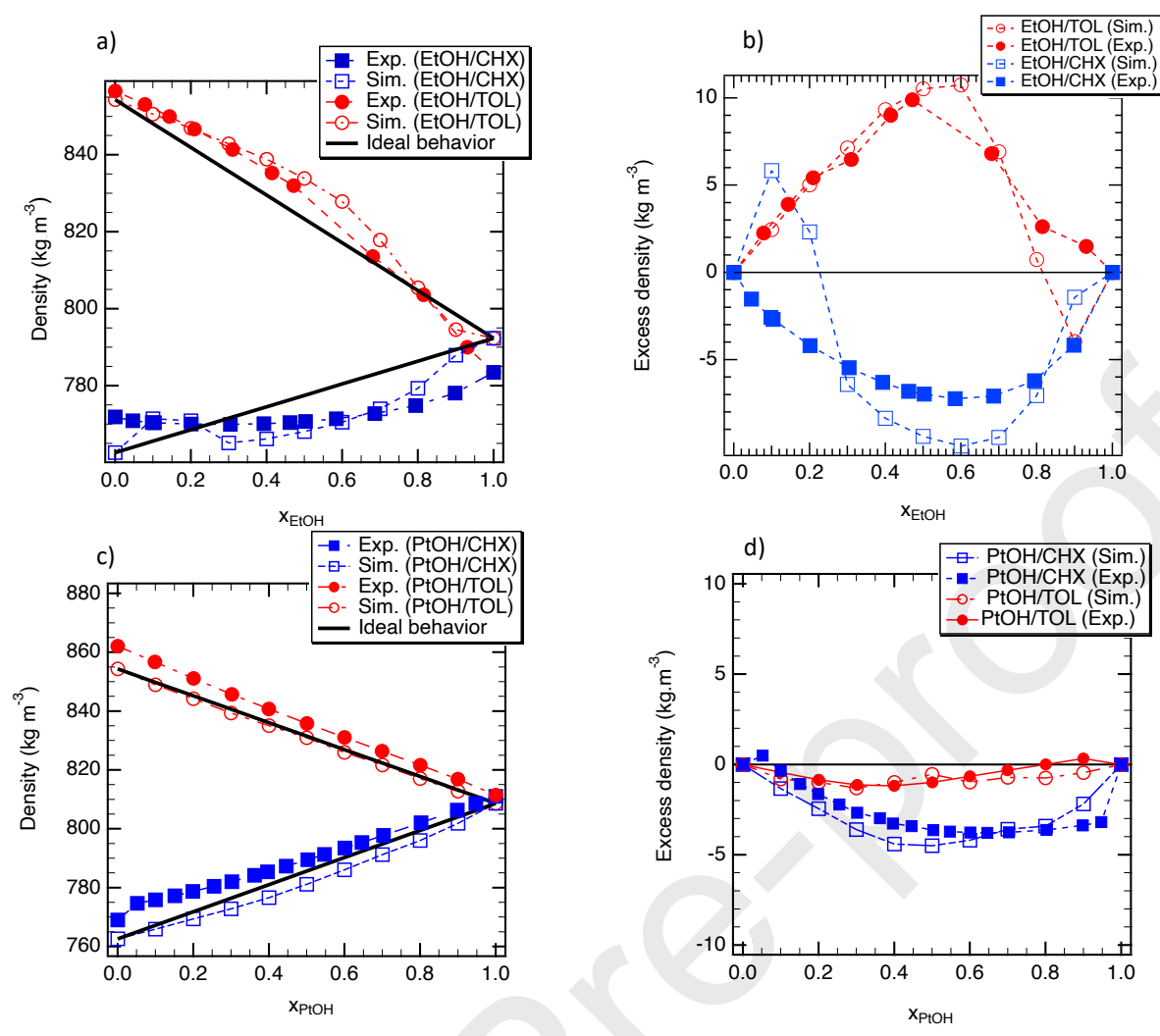

Figure 1. Density and excess density of EtOH/CHX and PtOH/CHX mixtures a) and b) and EtOH/TOL and PtOH/TOL mixtures c) and d). The average uncertainties about the density are around $15 \mathrm{~kg} / \mathrm{m}^{3}$. In part c) and d) the horizontal black line is a guide eyes to highlight $\mathrm{HOP}=0$.

to a larger HOP. Calculations were performed for both binary liquid mixtures. According to the study of Wang et al., the HOP of ideal particles homogeneously distributed is lower than 15.74 and a heterogeneous system exhibits a HOP greater than 15.74 [30]. The HOP is defined so that it is topologically invariant with the absolute distances between sites. Because the weights of the sites far from the central site decrease quickly with the distance (Eq. 1), the HOP approaches a constant with increasing number of sites. As example for some ideal systems with $\mathrm{N}=\mathrm{n}^{3}, \mathrm{n}=1,2,3, \ldots$, sites homogeneously distributed in a cubic box HOP approaches a constant value of 15.74 after $\mathrm{N}>729$. A HOP value lower than 15.74 shows that the system lacks of the statistic but is always homogenous. The HOP values of EtOH and $\mathrm{PtOH}$ in presence of $\mathrm{CHX}$ and TOL are reported in Figure 2a and Figure 2b. Figure S1b exhibits the time evolution of the HOP for the $\mathrm{EtOH} / \mathrm{CHX}$ and $\mathrm{PtOH} / \mathrm{CHX}$ for $\mathrm{x}_{\mathrm{EtOH}}=0.5$. As shown in Figure S1b HOP is well converged and the average uncertainties are found around 0.2 that involves equilibrated systems. As exhibited in Figure 2a the HOP of EtOH/TOL and EtOH/CHX are strongly higher than 15.74 that involves spatial heterogeneity. On the contrary, Figure $2 \mathrm{~b}$ depicts that the $\mathrm{HOP}$ of $\mathrm{PtOH} / \mathrm{TOL}$ and $\mathrm{PtOH} / \mathrm{CHX}$ are slightly higher than the bulk limit and smaller than the HOP calculated from EtOH mixtures. These results suggest that the spatial heterogeneity decreases as the alkyl chain length increases that is bore out from Figures S2c,f where the $\mathrm{HOP}$ of $\mathrm{PrOH}$ and $\mathrm{BuOH}$ are reported. To ensure that the system is well converged, the mechanical equilibrium was verified by calculating the configurational and the total pressure for the most heterogeneous systems i.e. EtOH/CHX for $\mathrm{x}_{\mathrm{EtOH}}=0.4$. Figure S1c highlights that the configurational pressure into the three directions is similar that suggests that the system is well isotropic. Additionally, Figure S1c exhibits that the total pressure is constant that suggests that the mechanical equilibrium is well reached.

The decrease in HOP in presence of TOL molecules is the result of favorable interactions between the OH group and the aromatic cycle of TOL [4] allowing a higher dispersion/dilution of the alcohol molecules. Indeed, as shown in Figure $2 c$ the radial distribution function (RDF) between the hydrogen atom (HO) of the hydroxide group of the alcohol molecules and the centre of mass of the aromatic cycle shows a peak around $2.5 \AA$ corresponding to the 
Table 1. Extremum value of the excess density $\left(\mathrm{kg} \mathrm{m}^{-3}\right.$ and heterogeneity order parameter ( $\left.\mathrm{HOP}\right)$ for $\mathrm{MeOH}[4], \mathrm{EtOH}, \mathrm{PrOH}, \mathrm{BuOH}$ and $\mathrm{PtOH}$ in both CHX and TOL mixtures.

\begin{tabular}{cccccc}
\hline & $\mathrm{MeOH}$ & $\mathrm{EtOH}$ & $\mathrm{PrOH}$ & $\mathrm{BuOH}$ & $\mathrm{PtOH}$ \\
\hline $\mathrm{CHX}$ & -15 & -10 & -8 & -5 & -5 \\
TOL & 15 & 10 & 8 & 3 & 2 \\
HOP(TOL) & 19 & 17 & 16.1 & 15.9 & 15.7 \\
HOP(CHX) & 32 & 22 & 18.4 & 18.5 & 16.1
\end{tabular}

characteristic distance of a hydrogen bond [32, 33, 34, 5] that suggests a favorable interactions. On the contrary, Figure 2c shows an absence of peak at $2.5 \AA$ in presence of CHX suggesting no favorable interactions between alcohol and $\mathrm{CHX}$ molecules. That enhances thus the possibility to get nanophases from maximizing alcohol-alcohol interactions probably at the origin of the more pronounced non-ideal character of CHX with respect to TOL. Furthermore, Figure 2c clearly illustrates the fact that the alkyl chain length does not impact the short range correlations.

To understand the so-observed differences between TOL and CHX mixtures and the effect of the alkyl chain length, strength of the hydrophilic interactions are examined by means of the calculation of the interactions between the $\mathrm{OH}$ groups of alcohol molecules $\left(\mathrm{E}_{\mathrm{OH}-\mathrm{OH}}\right)$ or from the Kirkwood-Buff integrals indirectly calculated by using $\mathrm{RDF}$ [4]. In this work, we opted for a direct evaluation of $\mathrm{E}_{\mathrm{OH}-\mathrm{OH}}$. To do so the electrostatic and the van der Waals interactions have been consideblack. Details of calculations are reported in the supporting information. We report in Figure $3 \mathrm{a} \mathrm{E}_{\mathrm{OH}-\mathrm{OH}}$ as a function of $x_{\mathrm{Alcohol}}$ in case of $\mathrm{CHX}$ mixtures. As shown in Figure $3 \mathrm{a}$ at low molar fraction of $\mathrm{EtOH} \mathrm{E}_{\mathrm{OH}-\mathrm{OH}}$ is higher than in pure ethanol liquid. That involves strong interactions between EtOH molecules at low concentration. Indeed, as shown in Figure 3c EtOH molecules self-assembly to maximize hydrophilic interactions by generating alcohol nanophases at the origin of the spatial heterogeneity as related in Figure 2a. As highlighted from Figure 3a and Figure 3d this phenomenon is not observed with $\mathrm{PtOH} / \mathrm{CHX}$ mixture that behaves a usual behavior i.e. a decrease in $\mathrm{E}_{\mathrm{OH}-\mathrm{OH}}$ as $\mathrm{x}_{\mathrm{PtOH}}$ increases. Formation of nanophases is less pronounced with PtOH given the favorable hydrophobic interactions between the long alkyl chain and CHX. There is then a balance between hydrophilic and hydrophobic interactions controlled from the alkyl chain length. These results allow us to well understand the increase in $\mathrm{HOP}$ and non-ideality of $\mathrm{EtOH} / \mathrm{CHX}$ mixture in relation with $\mathrm{PtOH} / \mathrm{CHX}$ one from the formation of EtOH nanophases resulting of the increase in hydrophilic alcohol interactions to maximize them. Similar calculations have been performed on the toluene mixtures. Figure $3 \mathrm{~b}$ exhibits that toluene mixtures follow similar trends that observed in $\mathrm{PtOH} / \mathrm{CHX}$ mixtures i.e. an increase of favorables alcohol-alcohol interactions as the molar fraction of alcohol increases that suggests less pronounced alcohol nanophases. That is in line with the small value in HOP and the less pronounced non-ideal character than the CHX mixture. As shown in Figure $2 \mathrm{c}$ that is the result of favorable interactions between the $\mathrm{OH}$ groups and the aromatic cycle that is in favor of the easier homogenization between both components.

It is well known that alcohols molecules are organized in aggregates/clusters from molecules connected them from hydrogen bonds $[28,35]$. The nanophases are then probably built from assembly of these aggregates [4]. In the pure liquid phase these aggregates are correlated at the mesoscopic range that can be evidenced from a prepeak in the total structure factor $(\mathrm{S}(\mathrm{Q}))[36,4]$. While radial distribution functions provide molecular information at short range $\mathrm{S}(\mathrm{Q})$ is a spatial window on the long range correlations. Recently, it has been shown that the prepeak in $S(Q)$ could be related to the main peak of the partial structure factor between the oxygen and the hydrogen atoms of different alcohol molecules $\left(\mathrm{S}_{\mathrm{HO}-\mathrm{OH}}(\mathrm{Q})\right)$. Calculation of $\mathrm{S}_{\mathrm{HO}-\mathrm{OH}}(\mathrm{Q})$ can be found elsewhere $[33,34]$ and is detailed in the supporting information. We report in Figure $4 \mathrm{a} \mathrm{S}_{\mathrm{HO}-\mathrm{OH}}(\mathrm{Q})$ as a function of $\mathrm{x}_{\mathrm{EtOH}}$. For $\mathrm{x}_{\mathrm{EtOH}}=1.0$ we observe a main peak around $0.9 \AA^{-1}$ that survives at $\mathrm{x}_{\mathrm{EtOH}}=0.9$ and disappears at $\mathrm{x}_{\mathrm{EtOH}}=0.5$. However Figure 5a clearly shows the presence of clusters in $\mathrm{EtOH} / \mathrm{CHX}$ mixture for a molar fraction of 0.5 . The disappearance of the peak at $\mathrm{x}_{\mathrm{EtOH}}=0.5$ involves then an absence of the long range correlations between aggregates. That is the result of the formation of uncorrelated nanophases formed from small clusters as shown in Figure 5a. Indeed, when the aggregates are confined into the nanophases the long range correlations cannot develop. 

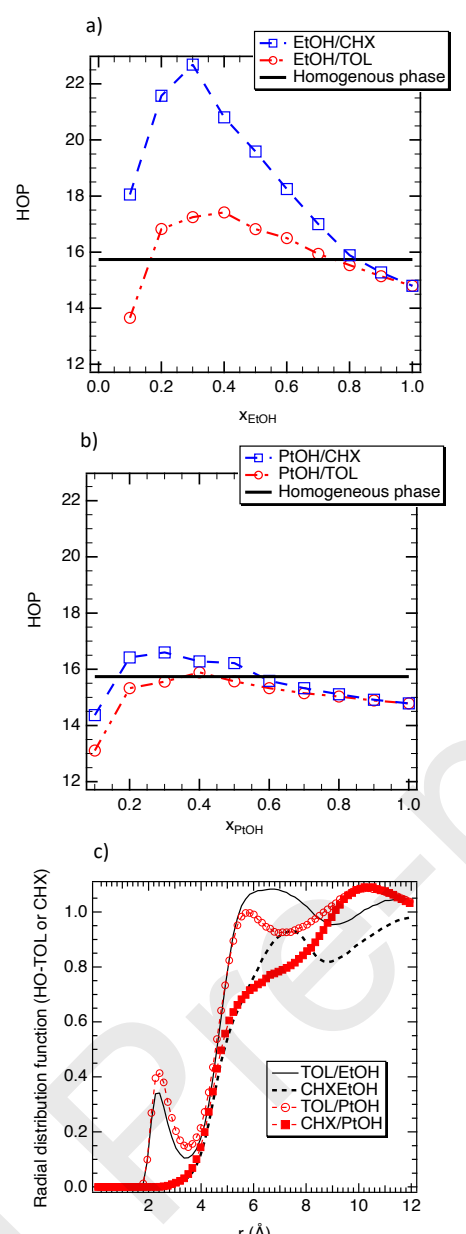

$r(\AA)$

Figure 2. $\mathrm{HOP}$ of $\mathrm{EtOH}$ a) and $\mathrm{PtOH}$ b) for both TOL and $\mathrm{CHX}$ binary mixtures as a function of the molar fraction of alcohol. The average uncertainties about the $\mathrm{HOP}$ are around 0.8 . c) Radial distribution functions between the hydrogen atoms of $\mathrm{OH}$ groups of EtOH and $\mathrm{PtOH}$ and the centre of mass of toluene molecules in both $\mathrm{CHX}$ and TOL mixtures at $\mathrm{x}_{\mathrm{Alcohol}}=0.5$.

Contrary to the $\mathrm{EtOH}$, Figure $4 \mathrm{~b}$ shows that the main peak of $\mathrm{S}_{\mathrm{HO}-\mathrm{OH}}(\mathrm{Q})$ calculated in the PtOH/CHX mixtures is still present at $\mathrm{x}_{\mathrm{PtOH}}=0.5$. Interestingly, as shown in Table $\mathrm{S} 1$ box lengths were found between $36 \AA$ and $45 \AA$ involving a unit momentum transfer vector between $0.175 \AA^{-1}$ and $0.139 \AA^{-1}$. Peak in Figure $4 \mathrm{~b}$ is found around 0.9 $\AA^{-1}$ beyond $0.175 \AA^{-1}$ that seems validate our factor structure calculation from 500 molecules. However, to ensure that the peak observed in Figure $4 \mathrm{~b}$ is meaningful from 500 molecules, MD simulations with a total number of 3000 molecules for a molar fraction in $\mathrm{PtOH}$ of 0.5 was performed that corresponds to the higher minimum $\mathrm{Q}$ value. From 3000 molecules box length is found around $84 \AA$ that corresponds to a unit momentum transfer vector of $0.075 \AA^{-1}$. Figure S3 exhibits that the partial structure factor obtained from both 500 and 3000 molecules are very similar as well the location minimum value of $\mathrm{Q}$ that validate our simulations using 500 molecules.

The fact that the main peak of $\mathrm{S}_{\mathrm{HO}-\mathrm{OH}}(\mathrm{Q})$ calculated in the $\mathrm{PtOH} / \mathrm{CHX}$ mixtures is still present highlights that the clusters are always correlated that is due to the absence of nanophases of $\mathrm{PtOH}$ as reported in Figure $3 \mathrm{~d}$. This result is corroborated by the calculation of cluster size distribution reported in Figure $5 \mathrm{~b}$ where clusters are observed from $\mathrm{X}_{\mathrm{PtOH}}=1$ to $\mathrm{X}_{\mathrm{PtOH}}=0.5$. Furthermore, the presence of the peak at $0.9 \AA^{-1}$ concomitant to the absence of nanophases involves thus a dilution of aggregates rather the dilution of $\mathrm{PtOH}$ molecules into the $\mathrm{CHX}$. Formation of aggregates is controlled by hydrogen bonds between hydroxide groups while dilution of clusters is ruled by favorable hydrophobic interactions between alkyl chain and the CHX. These interactions were quantified from the calculation of the total interactions between the alkyl chain of alcohol (Alc) and the CHX ( $\left.\mathrm{E}_{A l c-C H X}\right)$ and TOL $\left(\mathrm{E}_{A l c-T O L}\right)$. We report in 
a)
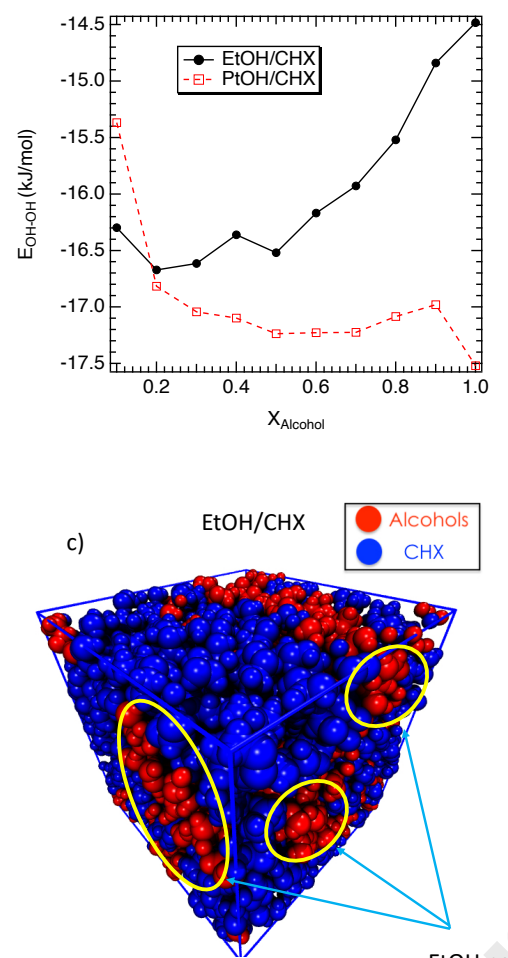

b)

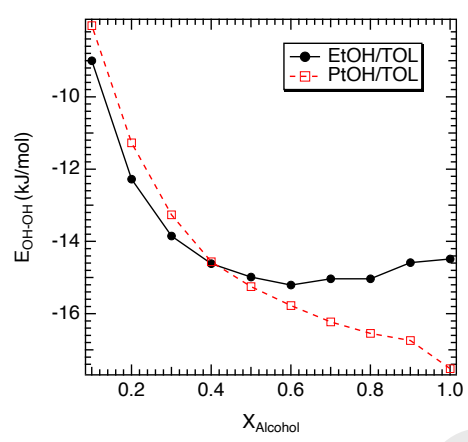

d)

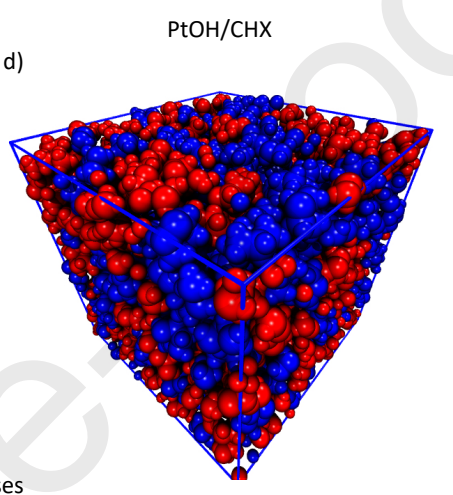

Figure 3. Calculated energy between the $\mathrm{OH}$ groups of alcohol molecules as a function of the molar fraction of alcohol into the CHX a) and TOL b) mixtures. Snapshots of $\mathrm{EtOH} / \mathrm{CHX}$ c) and $\mathrm{PtOH} / \mathrm{CHX}$ d) at $\mathrm{x}_{\mathrm{Alcohol}}=0.5$.

Figure 6a $\mathrm{E}_{A l c-C H X}$ as a function of the molar fraction of alcohol for both EtOH and PtOH. As shown in Figure 6a $\mathrm{E}_{P t O H-C H X}$ is lower than $\mathrm{E}_{\mathrm{E} t \mathrm{OH}-\mathrm{CHX}}$ involving that the hydrophobic interactions between $\mathrm{PtOH}$ and $\mathrm{CHX}$ molecules are most favorable and then a better dilution of the $\mathrm{PtOH}$ and a decrease of spatial heterogeneity in comparison with EtOH.

Regarding to the EtOH/TOL and PtOH/TOL similar results were obtained to a lesser extent. First, Figure 4a shows the disappearance of the main peak of $\mathrm{S}_{\mathrm{HO}-\mathrm{OH}}(\mathrm{Q})$ at $\mathrm{x}_{\mathrm{EtOH}}=0.5$ whereas Figure $4 \mathrm{~b}$ highlights its persistence in case of PtOH/TOL mixtures. These behaviors could be understood in terms of nanophases of aggregates, spatial heterogeneity and uncorrelated aggregates less pronounced that with CHX (see Figure 2). Presence of clusters is highlighted from Figure 5b. Indeed this figure shows a similar shape of the cluster size distribution between TOL and CHX mixtures and shed light thus on the existence of the aggregates into the TOL mixtures. Difference between $\mathrm{PtOH}$ and $\mathrm{EtOH}$ is the result of the hydrophobic interactions between TOL and alcohol. Indeed, Figure 6b shows that the hydrophobic interactions in case of $\mathrm{PtOH}$ mixtures are more favorable than in the EtOH mixtures. That is probably the consequence of the increase in size of alkyl chain. Interestingly, Figure 6a and Figure 6b shows that the difference in hydrophobic interactions between $\mathrm{EtOH}$ and $\mathrm{PtOH}$ is higher in case of $\mathrm{CHX}$ mixture comparatively to the TOL one. That is the result of the strong interactions between the $\mathrm{OH}$ group of the alcohol and the aromatic cycles (see Figure 2c). 

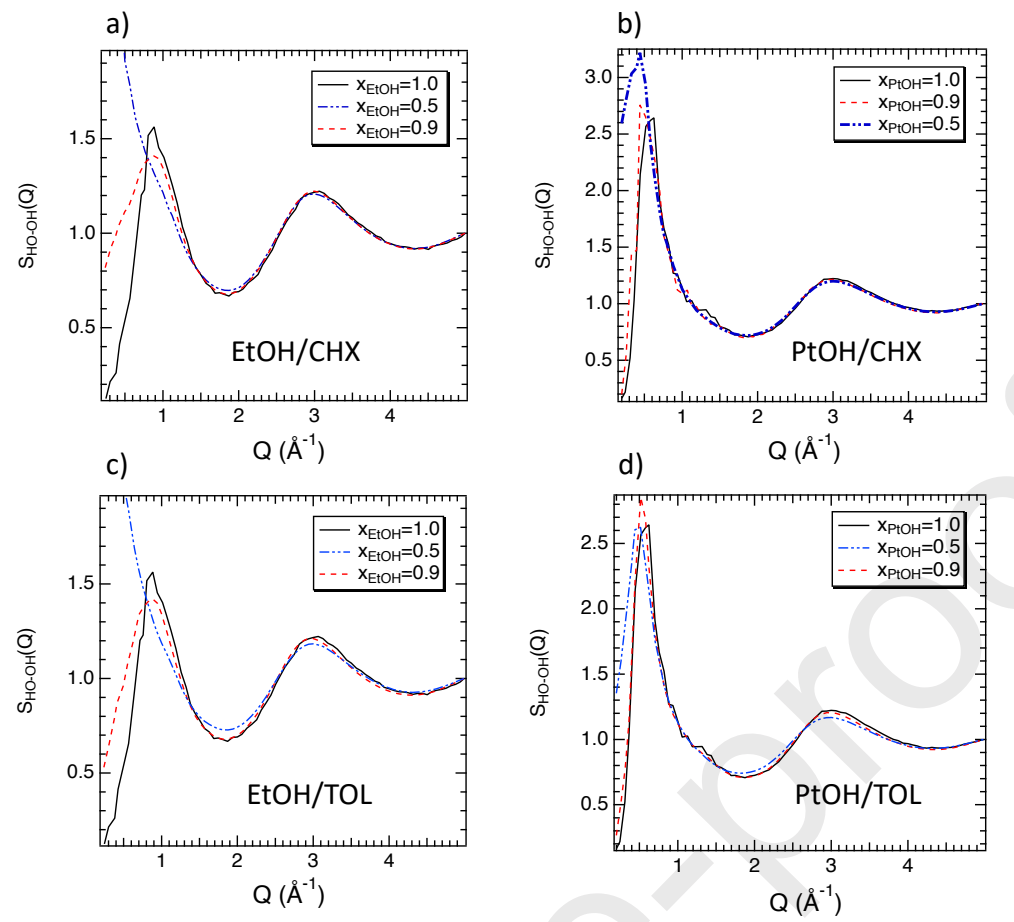

Figure 4. Partial structure factor $\left(\mathrm{S}_{\mathrm{HO}-\mathrm{OH}}(\mathrm{Q})\right)$ of $\mathrm{EtOH} / \mathrm{CHX}$ a), $\left.\left.\left.\mathrm{PtOH} / \mathrm{CHX} \mathrm{b}\right), \mathrm{EtOH} / \mathrm{TOL} \mathrm{c}\right), \mathrm{PtOH} / \mathrm{TOL} \mathrm{d}\right)$ as a function of the molar fraction of alcohol.

\section{Conclusion}

In this work EtOH/TOL, EtOH/CHX, PtOH/TOL and PtOH/CHX binary mixtures have been examined from molecular dynamics simulations to evaluate the role of the alkyl chain length on the non-ideality and the microstructure. We exhibited a strong deviation from the ideality of shorter alcohols due to formation of nanophases of uncorrelated aggregates. Clustering is controlled by hydrophilic interactions between hydroxide groups. Alcohol molecules self-assembly to maximize hydrophilic interactions by generating alcohol nanophases at the origin of the spatial heterogeneity and non-ideality. We have shown that $\mathrm{EtOH}$ and $\mathrm{PtOH}$ molecules were more diluted into the TOL mixtures given the favorable $\pi-\mathrm{OH}$ interactions. We have evidenced that the increase in alkyl chain size decreases the spatial heterogeneity due to the favorable hydrophobic interactions between the alkyl chain and the cycle of CHX and TOL leading to a better homogenization of alcohol molecules in form of aggregates. From larger alcohols hydrogen bonds are in competition with hydrophobic interactions allowing a better dispersion of alcohol molecules gatheblack in aggregates into the apolar solvent.

\section{Author contributions}

I.E. and A.G. carried out molecular dynamics simulations and wrote manuscript.

\section{Competing Financial Interest}

The authors declare no competing financial interests.

\subsection{Acknowledgements}

The authors are grateful to the "CNRS" for its financial support through the programs PEPS Infinity and PICS Waterloo 
a)

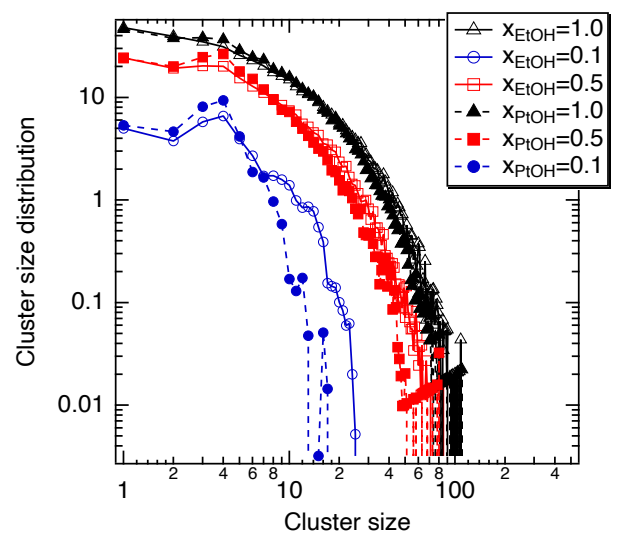

b)

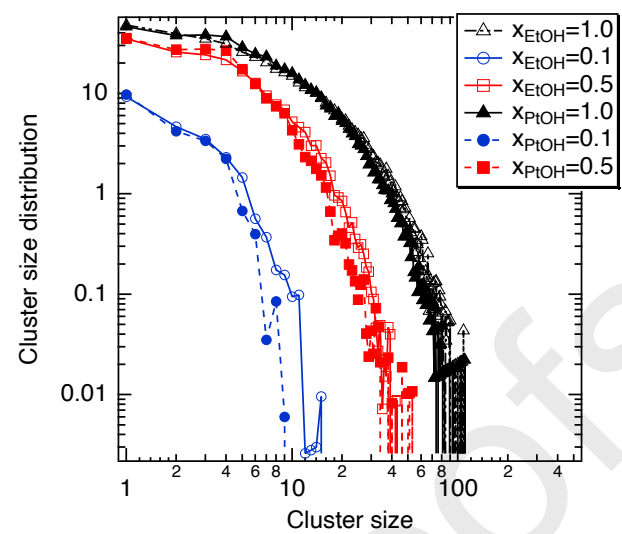

Figure 5. Cluster size distribution as a function of molar fraction of alcohol in CHX a) and TOL b) mixtures.

a)

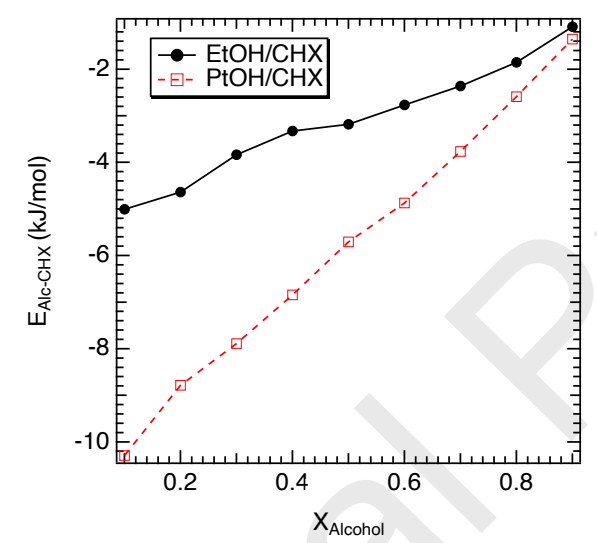

b)

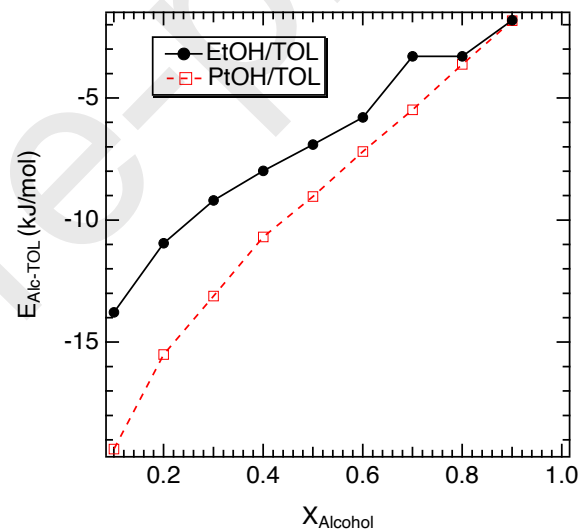

Figure 6. Calculated energy between the alkyl chain of alcohol molecules and CHX a) and TOL b) as a function of the molar fraction of alcohol.

\section{References}

[1] J. Kim, K. Lee, S. Kim, Pervaporation separation of water from ethanol through polymide composite membranes, J. Membr. Sci. 169 (2000) 81.

[2] N. Hilmioglu, Bioethanol recovery using the pervaporation separation technique, Manage. Environ. Qual. 20 (2009) 165.

[3] Q. Kang, J. Huybrechts, B.-V. der Bruggen, J. Baeyens, T. Tan, R. Dewil, Hydrophilic membranes to replace molecular sieves in dewatering the bio-ethanol/water azeotropic mixture, Separation and Purification Technology 136 (2014) 144.

[4] I. Essafri, A. Ghoufi, Microstructure of nonideal methanol binary liquid mixtures, Phys. Rev. E 99 (2019) 062607. doi:10.1103/PhysRevE.99.062607.

[5] A. Ghoufi, Molecular origin of the prepeak in the structure factor of alcohols, J. Phys. Chem. B 124 (2020) 11501-11509.

[6] G. N. Swamy, G. Dharmaraju, G. K. Raman, Excess volumes of toluene mixtures with some alcohols at 303.15k, Canadian Journal of Chemistry 58 (3) (1980) 229-230. doi:10.1139/v80-037.

[7] C. B. Kretschmer, R. Wiebe, Thermodynamics of alcohol-hydrocarbon mixtures, The Journal of Chemical Physics 22 (10) (1954) 1697-1701. doi:10.1063/1.1739878.

[8] R. Thiyagarajan, L. Palaniappan, Molecular interaction study of two aliphatic alcohols with cyclohexane, CSIR (2008) 852-856.

[9] P. S. Nikam, B. S. Jagdale, A. B. Sawant, M. Hasan, Densities and viscosities of binary mixtures of toluene with methanol, ethanol, propan1-ol, butan-1-ol, pentan-1-ol, and 2-methylpropan-2-ol at (303.15, 308.15, 313.15) k, Journal of Chemical \& Engineering Data 45 (4) (2000) 559-563. doi:10.1021/je990317i.

[10] L. Hennous, A. A. Hamid, R. Lefort, D. Morineau, P. Malfreyt, A. Ghoufi, Crossover in structure and dynamics of a primary alcohol induced by hydrogen-bonds dilution, J. Chem. Phys. 141 (2014) 204503. 
[11] Požar, Lovrinčević, Zoranić, Primorać, Sokolić, F. A. Perera, Micro-heterogenity versus clustering in binary mixtures of ethanol with water or alkanes, Phys. Chem. Chem. Phys. 18 (2016) 23971.

[12] M. Mhanna, R. Lefort, L. Noirez, D. Morineau, Microstructure and concentration fluctuations in alcohol-toluene and alcohol-cyclohexane binary liquids: A small angle neutron scattering study, J. Mol. Liquids 218 (2016) 198.

[13] M. A. Tomza, P.; Czarnecki, Microheterogeneity in binary mixtures of propyl alcohols with water: Nir spectroscopic, two-dimensional correlation and multivariate curve resolution study, Journal of Molecular Liquids 209 (2015) 115 - 120. doi:https://doi.org/10.1016/j.molliq.2015.05.033.

[14] E. Vokacova, Z. S.; Pluharova, Understanding structure and dynamics of organic liquid mixtures by molecular simulations, Journal of Molecular Liquidsdoi:https://doi.org/10.1016/j.molliq.2019.04.055.

[15] H. C. Van Ness, J. Van Winkle, H. H. Richtol, H. B. Hollinger, Infrared spectra and the thermodynamics of alcohol-hydrocarbon systems, The Journal of Physical Chemistry 71 (5) (1967) 1483-1494. doi:10.1021/j100864a046.

[16] A. N. Fletcher, Effect of carbon tetrachloride upon the self-association of 1-octanol, The Journal of Physical Chemistry 73 (7) (1969) 22172225. doi:10.1021/j100727a019.

[17] R. Tanaka, S. Toyama, Excess molar volumes and excess molar heat capacities for binary mixtures of (ethanol + benzene, or toluene, or o-xylene, or chlorobenzene) at a temperature of $298.15 \mathrm{k}$, Journal of Chemical \& Engineering Data 42 (5) (1997) 871-874. doi:10.1021/je9700479.

[18] S. C. P. Hwa, W. T. Ziegler, Temperature dependence of excess thermodynamic properties of ethanol-methylcyclohexane and ethanol-toluene systems1, The Journal of Physical Chemistry 70 (8) (1966) 2572-2593. doi:10.1021/j100880a025.

[19] Z. S. L. Morávková, Z. Wagner, J. Line, Volumetric behaviour of binary and ternary liquid systems composed of ethanol, isooctane, and toluene at temperatures from (298.15 to 328.15)k. experimental data and correlation, The Journal of Chemical Thermodynamics 43 (12) (2011) 1906 - 1916. doi:https://doi.org/10.1016/j.jct.2011.06.021.

[20] S. S. Patil, S. R. Mirgane, B. R. Arbad, Excess molar volumes and deviation in viscosities of binary liquid mixtures of acrylic esters with hexane-1-ol at 303.15 and 313.15k, Journal of Saudi Chemical Society 18 (6) (2014) 945 - 952. doi:https://doi.org/10.1016/j.jscs.2011.11.018.

[21] B. Satheesh, D. Sreenu, T. S. Jyostna, Thermodynamic and spectroscopic studies of intermolecular interactions between isoamyl alcohol and monocyclic aromatic non-ideal binary liquid mixtures, Chemical Data Collections 28 (2020) 100448. doi:https://doi.org/10.1016/j.cdc.2020.100448.

[22] D. Li, D. Xiao, X. Liu, J. Zhao, X. Xu, C. Wang, W. Wang, Densities and viscosities for the ternary system of (ethylcyclohexane + 1-butanol + ethyl octanoate) and corresponding binary systems at $t=(293.15-323.15) \mathrm{k}$, The Journal of Chemical Thermodynamics 150 (2020) 106173. doi:https://doi.org/10.1016/j.jct.2020.106173.

[23] O. Hiroyuki, Excess volumes of (1-pentanol + cyclohexane or benzene) at temperatures between $283.15 \mathrm{k}$ and $328.15 \mathrm{k}$, The Journal of Chemical Thermodynamics 34 (6) (2002) 849-859. doi:10.1006/jcht.2001.0940.

[24] R. Baskaran, T. R. Kubendran, Density and excess molar volume in a binary mixture of o-anisaldehyde and chlorobenzene at 303.15, 313.15, and 323.15 k, Russian Journal of Physical Chemistry 83 (3) (2009) 350-352. doi:10.1134/S0036024409030054.

[25] W. L. Jorgensen, D. S. Maxwell, J. Tirado-Rives, Development and testing of the opls all-atom force field on conformational energetics and properties of organic liquids, Journal of the American Chemical Society 118 (45) (1996) 11225-11236. doi:10.1021/ja9621760.

[26] W. Smith, T. Forester, Dlpoly2.0: A general-purpose parallel molecular dynamics simulation package, Journal of Molecular Graphics 14 (3) (1996) 136 - 141. doi:https://doi.org/10.1016/S0263-7855(96)00043-4.

[27] M.-L. Tan, B. T. Miller, J. Te, J. R. Cendagorta, B. R. Brooks, T. Ichiye, Hydrophobic hydration and the anomalous partial molar volumes in ethanol-water mixtures, J. Chem. Phys. 142 (2015) 064501.

[28] S. Noskov, G. Lamoureux, B. Roux, Molecular dynamics study of hydration in ethanol-water mixtures using a polarizable force field, J. Phys. Chem. B 109 (2005) 6705.

[29] R. Baskaran, T. Kubendran, Density and excess molar volume in a binary mixture of o-anisaldehyde and chlorobenzene at 303.15, 313.15, and 323.15 k, J. Phys. Chem. 83 (2009) 350.

[30] Y. Wang, G. A. Voth, Tail agrregation and domain diffusion in ionic liquids, J. Phys. Chem. B 110 (2006) 18601.

[31] S. Li, J. Bañuelos, P. Zhang, G. Feng, S. Dai, G. Rother, P. Cummings, Toward understanding the structural heterogeneity and ion pair stability in dicationic ionic liquids, Soft Matter 10 (2014) 9193

[32] A. Luzar, D. Chandler, Structure and hydrogen bond dynamics of water-dimethyl sulfoxide mixtures by computer simulations, The Journal of Chemical Physics 98 (10) (1993) 8160-8173. doi:10.1063/1.464521.

[33] A. Ghoufi, I. Hureau, R. lefort, D. Morineau, Hdrogen-bond-induced supermolecular assemblies in a nanoconfined tertiary alcohol, J. Phys. Chem. C 115 (2011) 36.

[34] A. Ghoufi, I. Hureau, D. Morineau, R. Renou, A. Szymczyk, Confinement of tert-butanol nanoclusters in hydrophilic and hydrophobic silica nanopores, J. Phys. Chem. C 117 (2013) 15203.

[35] A. Ghoufi, F. Artzner, P. Malfreyt, Physical properties and hydrogen-bonding network of water-ethanol mixtures from molecular dynamics simulations, The Journal of Physical Chemistry B 120 (4) (2016) 793-802. doi:10.1021/acs.jpcb.5b11776.

[36] R. Mhanna, R. Lefort, L. Noirez, D. Morineau, Microstructure and concentration fluctuations in alcohol-toluene and alcoholcyclohexane binary liquids: A small angle neutron scattering study, Journal of Molecular Liquids 218 (2016) 198 - 207. doi:https://doi.org/10.1016/j.molliq.2016.02.070. 


\title{
Effect of the alkyl chain length on the non-ideality and the microstructure of alcohol binary mixtures.
}

\author{
I. Essafri ${ }^{\mathrm{a}, * *}$, A. Ghoufi ${ }^{\mathrm{a}, *}$ \\ ${ }^{a}$ Institut de Physique de Rennes, IPR, CNRS-Université de Rennes 1, UMR CNRS 6251, 35042 Rennes, France
}

\begin{abstract}
In this study the microstructure of alcohol binary mixtures (toluene and cyclohexane) is investigated from molecular dynamics simulations. In case of cyclohexane mixtures, we show that the strong deviation from the ideality is the result of the formation of nanophases of alcohol molecules gatheblack in aggregates from hydrogen bonds leading to the spatial heterogeneity. Nanophases disappear as the alkyl chain size increases because the hydrophobic interactions counteracts the hydrogen bonds ones. The aggregates of short alcohol are found uncorrelated at the long range correlations which is related to an absence of the prepeak at low Q in the total structure factor. From toluene similar trends are observed with a lesser extend given the favorable $\pi$-OH interactions.
\end{abstract}

\section{(C) 2011 Published by Elsevier Ltd.}

Keywords: microstructure, binary alcohol mixture, spatial heterogeneity, molecular dynamics simulation

\section{Introduction}

Thermodynamical properties of binary mixtures are crucial to design and optimize the chemical industry $[1,2,3]$. These properties are important not only for a fundamental understanding of mixing processes, but also for many practical problems during the design of products, processes and industrial equipment. It is possible to pblackict the thermodynamic properties of binary systems from the properties of pure components, but in many cases such approaches are very inaccurate due to the complex interactions between components of the mixture such as hydrogen bonds, molecular association, dipole-dipole or induced dipolar interactions. As a consequence, deviations from an ideal behavior of thermodynamic mixture properties leads to a non-ideal mixture. These deviations can be captublack from the excess properties and are related to the unlike molecular intermolecular interactions between the components forming binary systems leading to specific spatial organization at the nanoscale [4,5]. Polar/apolar mixtures such as alcohol/alkane, alcohol/toluene, etc. represent a class of binary mixtures widely used in chemical industry with strong deviations from the ideality that explains that many works were devoted to the understanding of their non-ideality since 1970's.

It was then evidenced that the non-ideality of alcohol/alkane mixtures was the consequence of the balance between both hydrophobic and hydrophilic moiety $[6,7,8,9,10,11,12]$. Regarding to the propyl/alcohol mixture its nonideality behavior was correlated to the degree of self-association of the alcohol molecules [13] and to the structural changes [14]. According to Ness and fletcher, the anomalous behavior of the alcohol/alkane mixtures was related

\footnotetext{
*Corresponding author: aziz.ghoufi@univ-rennes1.fr

${ }^{* *}$ Corresponding author: ilham.essafri@ gmail.com
} 
to i) the formation of clusters between molecules through their hydrogen bonds and ii) the formation of complexes between alcohols and non-polar molecules $[15,16]$. Tanaka et al. have shown that excess thermodynamic properties of ethanol/toluene mixtures and other aromatic molecules are the result of the $\mathrm{OH}-\pi$ interaction between the ethanol and the aromatic molecule [17]. That was recently corroborated from a numerical study based on molecular simulation [4] and from Hwa and Ziegler that studied ethanol/toluene mixtures [18]. Later, Morávková et al interpreted the sign of the excess properties of the binary ethanol/toluene mixture as the result of the breaking of hydrogen bonding network [19].

Molecular understanding of the non-ideality can be performed from atomistic simulation that is a powerful approach to reveal the molecular structure of the binary systems. Recently the non-ideality of methanol/toluene and methanol/cyclohexane binary liquid mixtures and the connection with the structure at the nanoscale have been undertaken by means of molecular dynamics simulations [4]. The toluene was consideblack given its high hydrophobic character and its aromatic cycle at the origin of the miscibility of organic solvents in the alcohols. In the case of toluene, this non-ideality (positive excess density) and the miscibility have been ascribed with the specific interactions between toluene and methanol $(\mathrm{MeOH})$ leading to a breaking in the hydrogen bonding network involving clusters of different sizes and the spatial heterogeneity. The immiscibility and the non-ideality (negative excess density) of $\mathrm{MeOH} / \mathrm{CHX}$ mixtures were the result of the unfavorable interactions between $\mathrm{CHX}$ and $\mathrm{MeOH}$ leading to a selforganizing of $\mathrm{MeOH}$ molecules to form nanophases at the origin of the structural heterogeneity. Spatial/structural heterogeneity is related to the presence of different phases at the nanoscale; nanophase inducing a microstructure. Therefore, the terms microstructure and spatial/structural heterogeneity will be used equally.

While methanol and ethanol have been strongly investigated, alcohols with higher alkyl chain were less studied. However, to well apprehend the microscopic origin of the non ideality the dependence of effect of the alkyl chain length has to be undertaken. Indeed, alkyl chain length could strongly influence size of nanophases and then impact the degree of the non-ideality. Patil et al. have highlighted that the increase of chain length of acrylic esters from methyl- to butyl-acrylate involves a decrease in the excess molar volume function [20]. More recently, Satheesh et al. studied mixtures composed of isoamyl alcohol (IAA) and monocyclic aromatic, they showed that the non-ideality behavior of IAA and nitrobenzene binary liquid could be resulted from physical, chemical and structural molecular parameters, in which the $\mathrm{OH}-\pi$ interactions appears to be amongst the dominated interactions in such mixtures [21]. Li et al. have explained the deviations from ideality in 1-butanol/ethylcyclohexane binary mixture as the modification of the hydrogen bonding network of 1-butanol [22].

These studies evidenced then the role of the alkyl chain length on the deviation from the ideality of alcohols mixtures. As previously mentioned the non-ideality of mixture of simple alcohol such as methanol is intimately connected to the spatial heterogeneity induced by the formation of nanophases and the dilution of the hydrogen bonding network [4]. It would be then fundamentally relevant to explore the structure of alcohol mixtures with higher alkyl chain and to characterize the degree of spatial heterogeneity and its connection with the deviation from the ideality. In this work, we aim to extend our understanding of the interplay between the microstructure and the nonideality behavior of alcohol with the increase in alcohol alkyl chain length. To do so, equilibrium molecular dynamics simulations of mixtures of toluene (TOL) and cyclohexane (CHX) with ethanol (EtOH), propanol $(\mathrm{PrOH})$, butanol $(\mathrm{BuOH})$ and pentanol $(\mathrm{PtOH})$ are carried out. Indeed, toluene molecules are capable to induce strong interactions with alcohol molecules contrary to cyclohexane that allows us to investigate the role of the $\mathrm{OH}-\pi$ interactions. Let us note that these alcohols are fully miscible in both CHX and TOL solvents at whole range concentration $[8,9,23,24]$.

\section{Simulation Details}

The all-atom optimized potentials for liquid simulations force field (OPLS-AA) [25] were used to describe TOL, $\mathrm{CHX}, \mathrm{EtOH}, \mathrm{PrOH}, \mathrm{BuOH}$ and $\mathrm{PtOH}$ molecules. Molecular dynamics (MD) simulations were carried out using D1_Poly software package [26]. Non-bonding interactions are accounted through the Lennard-Jones (LJ) potential and the Coulombic interactions. The LJ parameters for unlike interactions were calculated using the Lorentz-Berthelot mixing rules. Electrostatic interactions were calculated from the Ewald sum using a convergence parameter of $1 \mathrm{E}^{-6}$. Temperature and pressure were fixed at $\mathrm{T}=298 \mathrm{~K}$ and $\mathrm{p}=1$ atm and were kept constant through the Berendsen thermostat and barostat with relaxation times of 0.1 and $0.5 \mathrm{ps}$, respectively. The integration of the equations of motion was performed using the Verlet integration scheme. The timestep is $1 \mathrm{fs}$ and configurations were saved every $100 \mathrm{fs}$ in each production run of $10 \mathrm{~ns}$ after an equilibration of $10 \mathrm{~ns}$. To be in line with previous study [4] number of molecules 
in each mixture is 500. Let us note that the thermal and the mechanical equilibria are found reached. MD simulations were performed for 11 different mole fractions from 0.0 to 1.0. Molecules have been randomly inserted in a cubic box of length of $50 \AA$. The final box lengths are provided in Table S1 of the Supporting Information. Calculations of partial structure factor, cluster size distributions and pairwise interactions are detailed in the supporting information.

\section{Results and discussion}

In Figure 1a we report the simulated, the experimental and the ideal densities of EtOH/CHX and EtOH/TOL binary mixtures. First, a good agreement between calculated and experimental densities is found what validates the so-used force field and crossed interactions. Figure S1a of the Supporting Information shows the time evolution of the density for the pure CHX and TOL. As shown in Figure S1a the density is well converged and the average uncertainty about the density are found around $15 \mathrm{~kg} / \mathrm{m}^{3}$ that involves equilibrated systems.For both EtOH/CHX and EtOH/TOL mixtures Figure 1a exhibits strong deviations from ideal density calculated from the pure component densities such as $\rho^{\text {ideal }}=x_{\mathrm{EtOH}} \rho_{E t O H}+\left(1-x_{\mathrm{EtOH}}\right) \rho_{T O L o r C H X}$. The non-ideality can be quantified from the calculation of the excess density corresponding to the difference between the simulated and the ideal densities. We report in Figure $1 \mathrm{~b}$ the excess density of both $\mathrm{EtOH} / \mathrm{CHX}$ and $\mathrm{EtOH} / \mathrm{TOL}$ binary mixtures as a function of $\mathrm{x}_{\mathrm{EtOH}}$. As shown in Figure $1 \mathrm{~b}$ the excess density of $\mathrm{EtOH} / \mathrm{TOL}$ mixture is rather positive contrary to the $\mathrm{EtOH} / \mathrm{CHX}$ mixtures that presents a negative contribution that is in fair agreement with experiment. However the two mixtures show a similar extremum in terms of absolute value around $x_{\mathrm{EtOH}}=0.6$, a maximum for $\mathrm{EtOH} / \mathrm{TOL}$ and a minimum for EtOH/CHX. Regarding to the $\mathrm{EtOH} / \mathrm{CHX}$ mixture the excess density is first positive from $x_{\mathrm{EtOH}}=0.0$ to $x_{\mathrm{EtOH}}=0.2$ and becomes negative from $x_{\mathrm{EtOH}}=0.2$ to $x_{\mathrm{EtOH}}=0.9$. To examine the deviation of the non-ideality as a function of the alkyl chain length we report in Figure $1 \mathrm{c}$ the density of $\mathrm{PtOH} / \mathrm{CHX}$ and $\mathrm{PtOH} / \mathrm{TOL}$ as a function of $x_{\mathrm{PtOH}}$. Contrary to EtOH the deviation from the ideality is less pronounced that $\mathrm{EtOH}$ what is corroborated from the calculation of the excess density reported in Figure 1d. Interestingly, a good concordance between calculated and experimental excess density was found what validates the so-used models. From CHX a minimum of $-5.0 \mathrm{~kg} \mathrm{~m}^{-3}$ is observed at $x_{\mathrm{PtOH}}=0.5$ against $-10.0 \mathrm{~kg} \mathrm{~m}^{-3}$ in case of EtOH. Interestingly, the non-ideal character is also less pronounced in $\mathrm{PtOH} / \mathrm{TOL}$ mixture than $\mathrm{PtOH} / \mathrm{CHX}$. The effect of alkyl chain on the non-ideality behavior is confirmed in Figures S2a,b,d,e of the supporting information where density and the excess density of propanol and butanol mixtures are reported. As shown in Figures S2a,b,d,e the deviation with respect to an ideal mixture gradually decreases from $\mathrm{EtOH}$ to $\mathrm{PtOH}$.

Interestingly, from the study of $\mathrm{MeOH}$ mixtures, it has been recently evidenced that these deviations were the results of the change in the structural topology leading to a spatial heterogeneity as a consequence of the difference in the interactions between both components of the binary liquid mixtures [4]. Indeed, the positive excess density was ascribed with the specific interactions between toluene and methanol leading to a breaking in the hydrogen bonding network involving clusters of different sizes and the spatial heterogeneity. The negative excess density of $\mathrm{MeOH} / \mathrm{CHX}$ mixtures were the result of the unfavorable interactions between $\mathrm{CHX}$ and MeOH leading to a self-organizing of $\mathrm{CHX}$ molecules to form hydrophobic nanophases at the origin of the spatial heterogeneity. Therefore the increases in alkyl chain length have to increase the hydrophobic interactions between aprotic solvent from their alkyl chain involving thus a higher dilution of the alcohol. Figure 1 and Figures S2a,b,d,e confirm this behavior. That is bears out from Table 1 where the maximum of excess density as a function of the mixture is reported. The positive and the negative excess density can be then understood in terms of molecular interactions and spatial heterogeneity at the nanoscale $[27,28,29,4]$.

The spatial heterogeneity can be quantified from the calculation of the heterogeneity order parameter (HOP) $[30,31]$ obtained from

$$
H O P=\frac{1}{N_{s}} \sum_{i=1}^{N_{s}} \sum_{j=1}^{N_{s}} \exp \left(-\frac{r_{i j}^{2}}{2 \sigma^{2}}\right)
$$

such that $N_{s}$ is the total number of sites in the system that represents the centres of mass of molecules, $\mathrm{r}_{i j}$ is the distance between sites $i$ and $j$, and $\sigma=\frac{L}{N_{s}^{\frac{1}{3}}}, L$ is the length of the cubic simulation box. The value of HOP increases with the expansion of the spatial heterogeneity because a tighter packing of sites results in a smaller $\mathbf{r}_{i j}$, which leads 

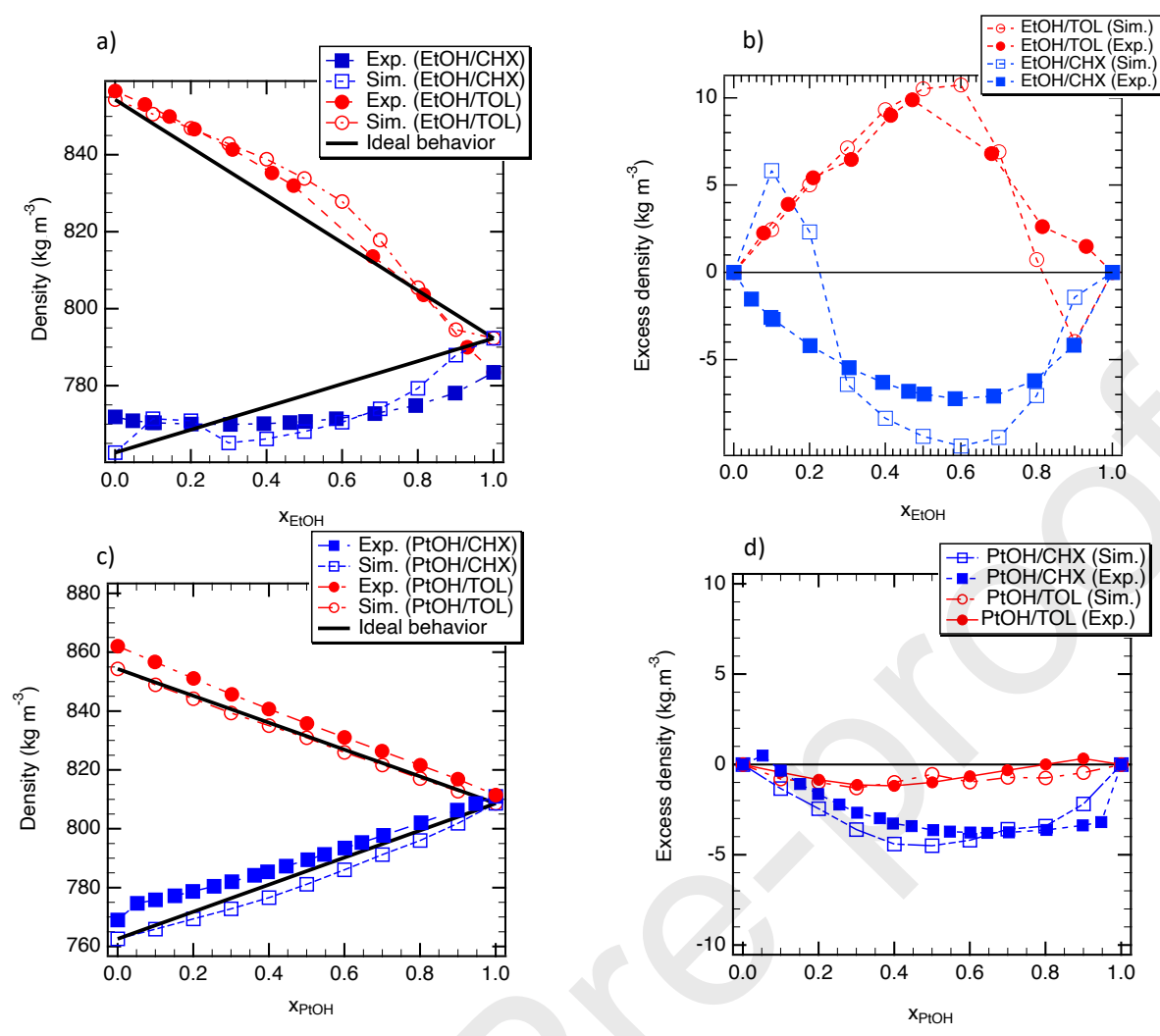

Figure 1. Density and excess density of EtOH/CHX and PtOH/CHX mixtures a) and b) and EtOH/TOL and PtOH/TOL mixtures c) and d). The average uncertainties about the density are around $15 \mathrm{~kg} / \mathrm{m}^{3}$. In part c) and d) the horizontal black line is a guide eyes to highlight $\mathrm{HOP}=0$.

to a larger HOP. Calculations were performed for both binary liquid mixtures. According to the study of Wang et al., the HOP of ideal particles homogeneously distributed is lower than 15.74 and a heterogeneous system exhibits a HOP greater than 15.74 [30]. The HOP is defined so that it is topologically invariant with the absolute distances between sites. Because the weights of the sites far from the central site decrease quickly with the distance (Eq. 1), the HOP approaches a constant with increasing number of sites. As example for some ideal systems with $\mathrm{N}=\mathrm{n}^{3}, \mathrm{n}=1,2,3, \ldots$, sites homogeneously distributed in a cubic box HOP approaches a constant value of 15.74 after $\mathrm{N}>729$. A HOP value lower than 15.74 shows that the system lacks of the statistic but is always homogenous. The HOP values of EtOH and $\mathrm{PtOH}$ in presence of $\mathrm{CHX}$ and TOL are reported in Figure 2a and Figure 2b. Figure S1b exhibits the time evolution of the HOP for the $\mathrm{EtOH} / \mathrm{CHX}$ and $\mathrm{PtOH} / \mathrm{CHX}$ for $\mathrm{x}_{\mathrm{EtOH}}=0.5$. As shown in Figure S1b HOP is well converged and the average uncertainties are found around 0.2 that involves equilibrated systems. As exhibited in Figure 2a the HOP of EtOH/TOL and EtOH/CHX are strongly higher than 15.74 that involves spatial heterogeneity. On the contrary, Figure $2 \mathrm{~b}$ depicts that the $\mathrm{HOP}$ of $\mathrm{PtOH} / \mathrm{TOL}$ and $\mathrm{PtOH} / \mathrm{CHX}$ are slightly higher than the bulk limit and smaller than the HOP calculated from EtOH mixtures. These results suggest that the spatial heterogeneity decreases as the alkyl chain length increases that is bore out from Figures S2c,f where the $\mathrm{HOP}$ of $\mathrm{PrOH}$ and $\mathrm{BuOH}$ are reported. To ensure that the system is well converged, the mechanical equilibrium was verified by calculating the configurational and the total pressure for the most heterogeneous systems i.e. EtOH/CHX for $\mathrm{x}_{\mathrm{EtOH}}=0.4$. Figure S1c highlights that the configurational pressure into the three directions is similar that suggests that the system is well isotropic. Additionally, Figure S1c exhibits that the total pressure is constant that suggests that the mechanical equilibrium is well reached.

The decrease in HOP in presence of TOL molecules is the result of favorable interactions between the OH group and the aromatic cycle of TOL [4] allowing a higher dispersion/dilution of the alcohol molecules. Indeed, as shown in Figure $2 c$ the radial distribution function (RDF) between the hydrogen atom (HO) of the hydroxide group of the alcohol molecules and the centre of mass of the aromatic cycle shows a peak around $2.5 \AA$ corresponding to the 
Table 1. Extremum value of the excess density $\left(\mathrm{kg} \mathrm{m}^{-3}\right.$ and heterogeneity order parameter ( $\left.\mathrm{HOP}\right)$ for $\mathrm{MeOH}[4], \mathrm{EtOH}, \mathrm{PrOH}, \mathrm{BuOH}$ and $\mathrm{PtOH}$ in both CHX and TOL mixtures.

\begin{tabular}{cccccc}
\hline & $\mathrm{MeOH}$ & $\mathrm{EtOH}$ & $\mathrm{PrOH}$ & $\mathrm{BuOH}$ & $\mathrm{PtOH}$ \\
\hline $\mathrm{CHX}$ & -15 & -10 & -8 & -5 & -5 \\
TOL & 15 & 10 & 8 & 3 & 2 \\
HOP(TOL) & 19 & 17 & 16.1 & 15.9 & 15.7 \\
HOP(CHX) & 32 & 22 & 18.4 & 18.5 & 16.1
\end{tabular}

characteristic distance of a hydrogen bond [32, 33, 34, 5] that suggests a favorable interactions. On the contrary, Figure 2c shows an absence of peak at $2.5 \AA$ in presence of CHX suggesting no favorable interactions between alcohol and $\mathrm{CHX}$ molecules. That enhances thus the possibility to get nanophases from maximizing alcohol-alcohol interactions probably at the origin of the more pronounced non-ideal character of CHX with respect to TOL. Furthermore, Figure 2c clearly illustrates the fact that the alkyl chain length does not impact the short range correlations.

To understand the so-observed differences between TOL and CHX mixtures and the effect of the alkyl chain length, strength of the hydrophilic interactions are examined by means of the calculation of the interactions between the $\mathrm{OH}$ groups of alcohol molecules $\left(\mathrm{E}_{\mathrm{OH}-\mathrm{OH}}\right)$ or from the Kirkwood-Buff integrals indirectly calculated by using $\mathrm{RDF}$ [4]. In this work, we opted for a direct evaluation of $\mathrm{E}_{\mathrm{OH}-\mathrm{OH}}$. To do so the electrostatic and the van der Waals interactions have been consideblack. Details of calculations are reported in the supporting information. We report in Figure $3 \mathrm{a} \mathrm{E}_{\mathrm{OH}-\mathrm{OH}}$ as a function of $x_{\mathrm{Alcohol}}$ in case of $\mathrm{CHX}$ mixtures. As shown in Figure $3 \mathrm{a}$ at low molar fraction of $\mathrm{EtOH} \mathrm{E}_{\mathrm{OH}-\mathrm{OH}}$ is higher than in pure ethanol liquid. That involves strong interactions between EtOH molecules at low concentration. Indeed, as shown in Figure 3c EtOH molecules self-assembly to maximize hydrophilic interactions by generating alcohol nanophases at the origin of the spatial heterogeneity as related in Figure 2a. As highlighted from Figure 3a and Figure 3d this phenomenon is not observed with $\mathrm{PtOH} / \mathrm{CHX}$ mixture that behaves a usual behavior i.e. a decrease in $\mathrm{E}_{\mathrm{OH}-\mathrm{OH}}$ as $\mathrm{x}_{\mathrm{PtOH}}$ increases. Formation of nanophases is less pronounced with PtOH given the favorable hydrophobic interactions between the long alkyl chain and CHX. There is then a balance between hydrophilic and hydrophobic interactions controlled from the alkyl chain length. These results allow us to well understand the increase in $\mathrm{HOP}$ and non-ideality of $\mathrm{EtOH} / \mathrm{CHX}$ mixture in relation with $\mathrm{PtOH} / \mathrm{CHX}$ one from the formation of EtOH nanophases resulting of the increase in hydrophilic alcohol interactions to maximize them. Similar calculations have been performed on the toluene mixtures. Figure $3 \mathrm{~b}$ exhibits that toluene mixtures follow similar trends that observed in $\mathrm{PtOH} / \mathrm{CHX}$ mixtures i.e. an increase of favorables alcohol-alcohol interactions as the molar fraction of alcohol increases that suggests less pronounced alcohol nanophases. That is in line with the small value in HOP and the less pronounced non-ideal character than the CHX mixture. As shown in Figure $2 \mathrm{c}$ that is the result of favorable interactions between the $\mathrm{OH}$ groups and the aromatic cycle that is in favor of the easier homogenization between both components.

It is well known that alcohols molecules are organized in aggregates/clusters from molecules connected them from hydrogen bonds $[28,35]$. The nanophases are then probably built from assembly of these aggregates [4]. In the pure liquid phase these aggregates are correlated at the mesoscopic range that can be evidenced from a prepeak in the total structure factor $(\mathrm{S}(\mathrm{Q}))[36,4]$. While radial distribution functions provide molecular information at short range $\mathrm{S}(\mathrm{Q})$ is a spatial window on the long range correlations. Recently, it has been shown that the prepeak in $S(Q)$ could be related to the main peak of the partial structure factor between the oxygen and the hydrogen atoms of different alcohol molecules $\left(\mathrm{S}_{\mathrm{HO}-\mathrm{OH}}(\mathrm{Q})\right)$. Calculation of $\mathrm{S}_{\mathrm{HO}-\mathrm{OH}}(\mathrm{Q})$ can be found elsewhere $[33,34]$ and is detailed in the supporting information. We report in Figure $4 \mathrm{a} \mathrm{S}_{\mathrm{HO}-\mathrm{OH}}(\mathrm{Q})$ as a function of $\mathrm{x}_{\mathrm{EtOH}}$. For $\mathrm{x}_{\mathrm{EtOH}}=1.0$ we observe a main peak around $0.9 \AA^{-1}$ that survives at $\mathrm{x}_{\mathrm{EtOH}}=0.9$ and disappears at $\mathrm{x}_{\mathrm{EtOH}}=0.5$. However Figure 5a clearly shows the presence of clusters in $\mathrm{EtOH} / \mathrm{CHX}$ mixture for a molar fraction of 0.5 . The disappearance of the peak at $\mathrm{x}_{\mathrm{EtOH}}=0.5$ involves then an absence of the long range correlations between aggregates. That is the result of the formation of uncorrelated nanophases formed from small clusters as shown in Figure 5a. Indeed, when the aggregates are confined into the nanophases the long range correlations cannot develop. 

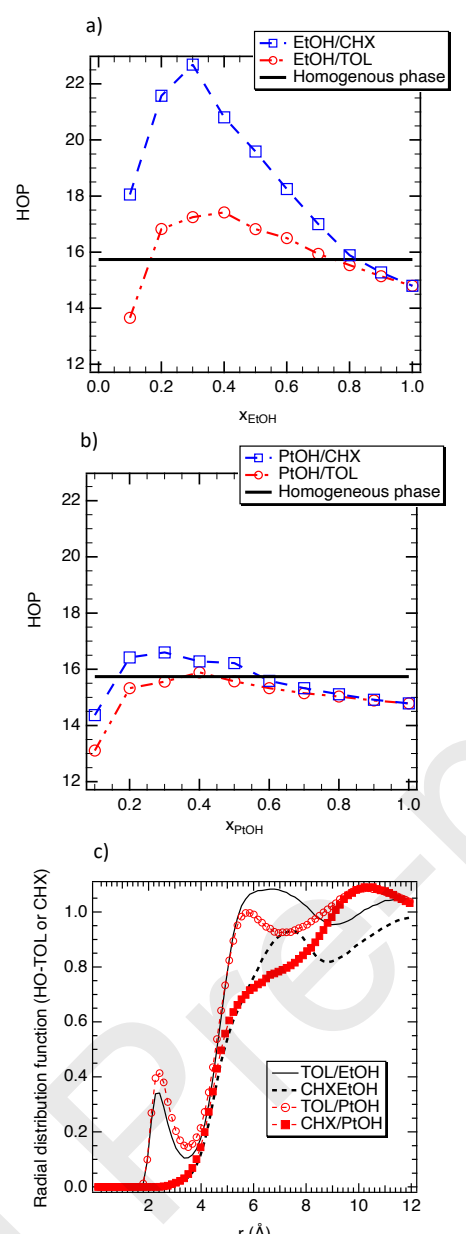

$r(\AA)$

Figure 2. $\mathrm{HOP}$ of $\mathrm{EtOH}$ a) and $\mathrm{PtOH}$ b) for both TOL and $\mathrm{CHX}$ binary mixtures as a function of the molar fraction of alcohol. The average uncertainties about the $\mathrm{HOP}$ are around 0.8 . c) Radial distribution functions between the hydrogen atoms of $\mathrm{OH}$ groups of EtOH and $\mathrm{PtOH}$ and the centre of mass of toluene molecules in both $\mathrm{CHX}$ and TOL mixtures at $\mathrm{x}_{\mathrm{Alcohol}}=0.5$.

Contrary to the $\mathrm{EtOH}$, Figure $4 \mathrm{~b}$ shows that the main peak of $\mathrm{S}_{\mathrm{HO}-\mathrm{OH}}(\mathrm{Q})$ calculated in the PtOH/CHX mixtures is still present at $\mathrm{x}_{\mathrm{PtOH}}=0.5$. Interestingly, as shown in Table $\mathrm{S} 1$ box lengths were found between $36 \AA$ and $45 \AA$ involving a unit momentum transfer vector between $0.175 \AA^{-1}$ and $0.139 \AA^{-1}$. Peak in Figure $4 \mathrm{~b}$ is found around 0.9 $\AA^{-1}$ beyond $0.175 \AA^{-1}$ that seems validate our factor structure calculation from 500 molecules. However, to ensure that the peak observed in Figure $4 \mathrm{~b}$ is meaningful from 500 molecules, MD simulations with a total number of 3000 molecules for a molar fraction in $\mathrm{PtOH}$ of 0.5 was performed that corresponds to the higher minimum $\mathrm{Q}$ value. From 3000 molecules box length is found around $84 \AA$ that corresponds to a unit momentum transfer vector of $0.075 \AA^{-1}$. Figure S3 exhibits that the partial structure factor obtained from both 500 and 3000 molecules are very similar as well the location minimum value of $\mathrm{Q}$ that validate our simulations using 500 molecules.

The fact that the main peak of $\mathrm{S}_{\mathrm{HO}-\mathrm{OH}}(\mathrm{Q})$ calculated in the $\mathrm{PtOH} / \mathrm{CHX}$ mixtures is still present highlights that the clusters are always correlated that is due to the absence of nanophases of $\mathrm{PtOH}$ as reported in Figure $3 \mathrm{~d}$. This result is corroborated by the calculation of cluster size distribution reported in Figure $5 \mathrm{~b}$ where clusters are observed from $\mathrm{X}_{\mathrm{PtOH}}=1$ to $\mathrm{X}_{\mathrm{PtOH}}=0.5$. Furthermore, the presence of the peak at $0.9 \AA^{-1}$ concomitant to the absence of nanophases involves thus a dilution of aggregates rather the dilution of $\mathrm{PtOH}$ molecules into the $\mathrm{CHX}$. Formation of aggregates is controlled by hydrogen bonds between hydroxide groups while dilution of clusters is ruled by favorable hydrophobic interactions between alkyl chain and the CHX. These interactions were quantified from the calculation of the total interactions between the alkyl chain of alcohol (Alc) and the CHX ( $\left.\mathrm{E}_{A l c-C H X}\right)$ and TOL $\left(\mathrm{E}_{A l c-T O L}\right)$. We report in 
a)
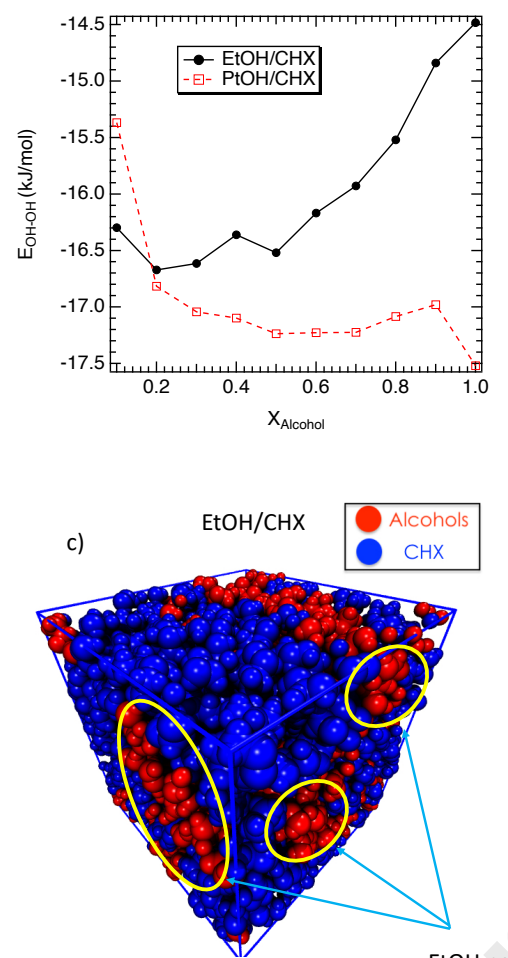

b)

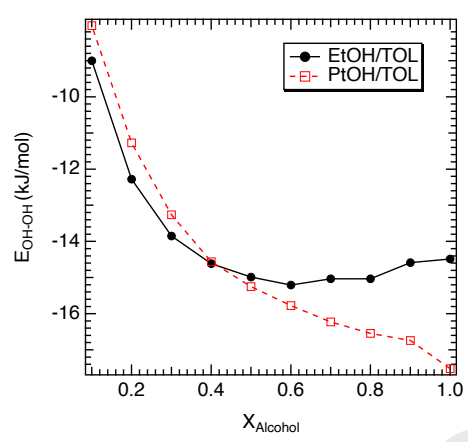

d)

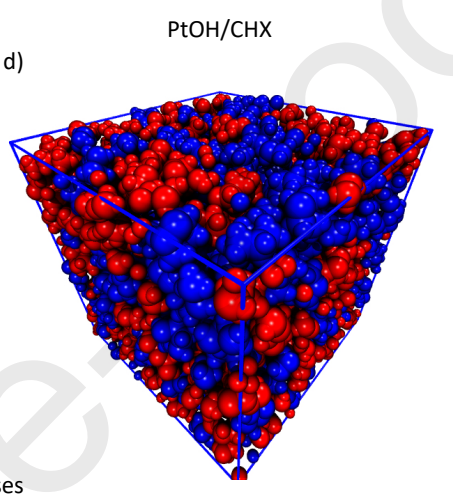

Figure 3. Calculated energy between the $\mathrm{OH}$ groups of alcohol molecules as a function of the molar fraction of alcohol into the CHX a) and TOL b) mixtures. Snapshots of $\mathrm{EtOH} / \mathrm{CHX}$ c) and $\mathrm{PtOH} / \mathrm{CHX}$ d) at $\mathrm{x}_{\mathrm{Alcohol}}=0.5$.

Figure 6a $\mathrm{E}_{A l c-C H X}$ as a function of the molar fraction of alcohol for both EtOH and PtOH. As shown in Figure 6a $\mathrm{E}_{P t O H-C H X}$ is lower than $\mathrm{E}_{\mathrm{E} t \mathrm{OH}-\mathrm{CHX}}$ involving that the hydrophobic interactions between $\mathrm{PtOH}$ and $\mathrm{CHX}$ molecules are most favorable and then a better dilution of the $\mathrm{PtOH}$ and a decrease of spatial heterogeneity in comparison with EtOH.

Regarding to the EtOH/TOL and PtOH/TOL similar results were obtained to a lesser extent. First, Figure 4a shows the disappearance of the main peak of $\mathrm{S}_{\mathrm{HO}-\mathrm{OH}}(\mathrm{Q})$ at $\mathrm{x}_{\mathrm{EtOH}}=0.5$ whereas Figure $4 \mathrm{~b}$ highlights its persistence in case of PtOH/TOL mixtures. These behaviors could be understood in terms of nanophases of aggregates, spatial heterogeneity and uncorrelated aggregates less pronounced that with CHX (see Figure 2). Presence of clusters is highlighted from Figure 5b. Indeed this figure shows a similar shape of the cluster size distribution between TOL and CHX mixtures and shed light thus on the existence of the aggregates into the TOL mixtures. Difference between $\mathrm{PtOH}$ and $\mathrm{EtOH}$ is the result of the hydrophobic interactions between TOL and alcohol. Indeed, Figure 6b shows that the hydrophobic interactions in case of $\mathrm{PtOH}$ mixtures are more favorable than in the EtOH mixtures. That is probably the consequence of the increase in size of alkyl chain. Interestingly, Figure 6a and Figure 6b shows that the difference in hydrophobic interactions between $\mathrm{EtOH}$ and $\mathrm{PtOH}$ is higher in case of $\mathrm{CHX}$ mixture comparatively to the TOL one. That is the result of the strong interactions between the $\mathrm{OH}$ group of the alcohol and the aromatic cycles (see Figure 2c). 

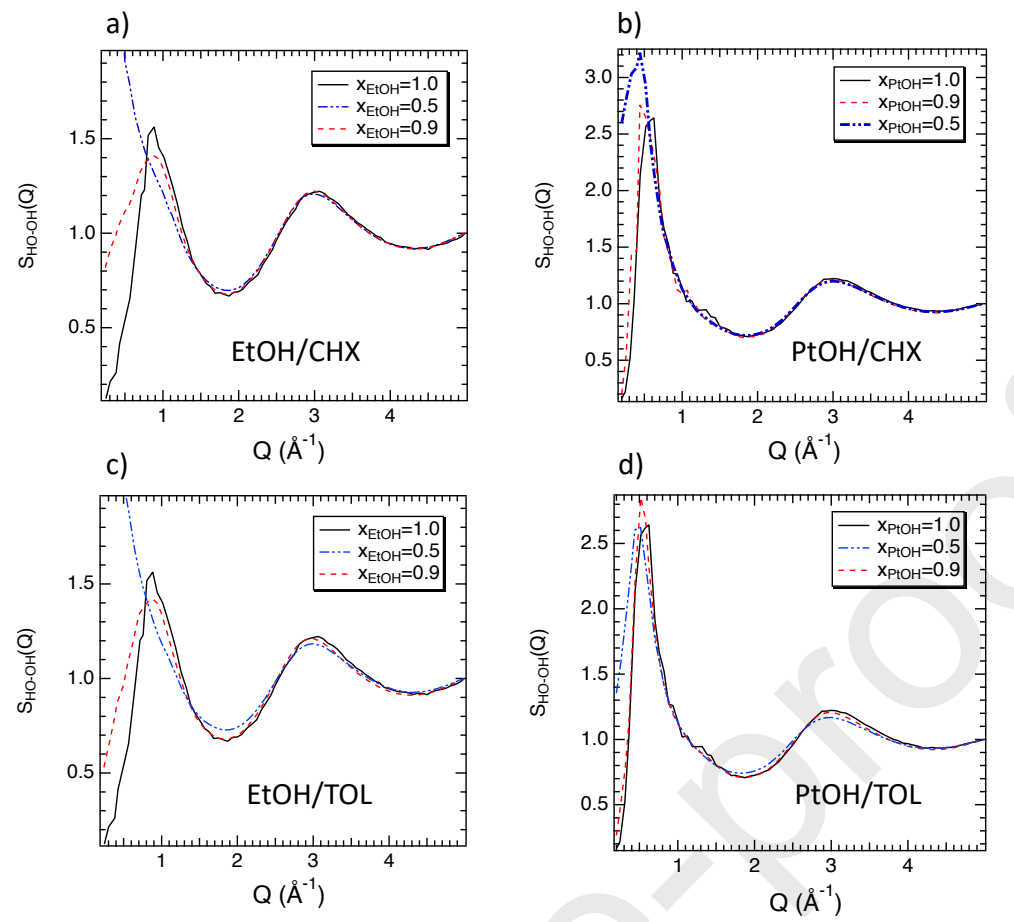

Figure 4. Partial structure factor $\left(\mathrm{S}_{\mathrm{HO}-\mathrm{OH}}(\mathrm{Q})\right)$ of $\mathrm{EtOH} / \mathrm{CHX}$ a), $\left.\left.\left.\mathrm{PtOH} / \mathrm{CHX} \mathrm{b}\right), \mathrm{EtOH} / \mathrm{TOL} \mathrm{c}\right), \mathrm{PtOH} / \mathrm{TOL} \mathrm{d}\right)$ as a function of the molar fraction of alcohol.

\section{Conclusion}

In this work EtOH/TOL, EtOH/CHX, PtOH/TOL and PtOH/CHX binary mixtures have been examined from molecular dynamics simulations to evaluate the role of the alkyl chain length on the non-ideality and the microstructure. We exhibited a strong deviation from the ideality of shorter alcohols due to formation of nanophases of uncorrelated aggregates. Clustering is controlled by hydrophilic interactions between hydroxide groups. Alcohol molecules self-assembly to maximize hydrophilic interactions by generating alcohol nanophases at the origin of the spatial heterogeneity and non-ideality. We have shown that $\mathrm{EtOH}$ and $\mathrm{PtOH}$ molecules were more diluted into the TOL mixtures given the favorable $\pi-\mathrm{OH}$ interactions. We have evidenced that the increase in alkyl chain size decreases the spatial heterogeneity due to the favorable hydrophobic interactions between the alkyl chain and the cycle of CHX and TOL leading to a better homogenization of alcohol molecules in form of aggregates. From larger alcohols hydrogen bonds are in competition with hydrophobic interactions allowing a better dispersion of alcohol molecules gatheblack in aggregates into the apolar solvent.

\section{Author contributions}

I.E. and A.G. carried out molecular dynamics simulations and wrote manuscript.

\section{Competing Financial Interest}

The authors declare no competing financial interests.

\subsection{Acknowledgements}

The authors are grateful to the "CNRS" for its financial support through the programs PEPS Infinity and PICS Waterloo 
a)

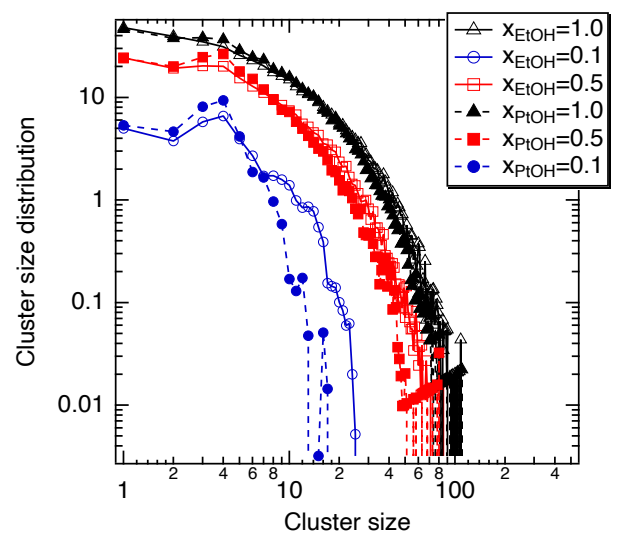

b)

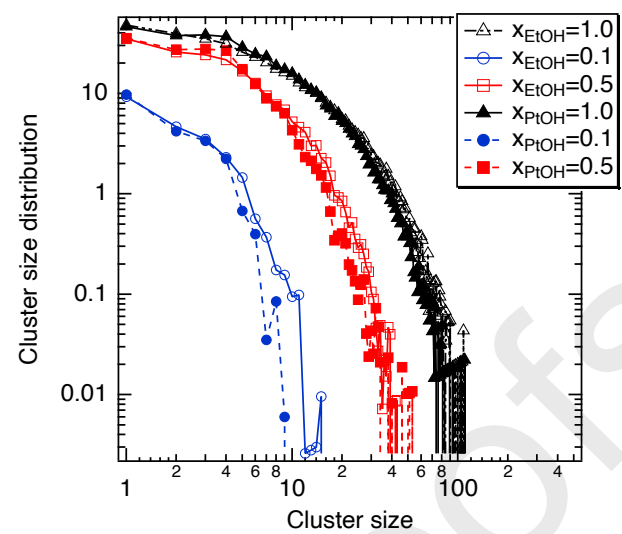

Figure 5. Cluster size distribution as a function of molar fraction of alcohol in CHX a) and TOL b) mixtures.

a)

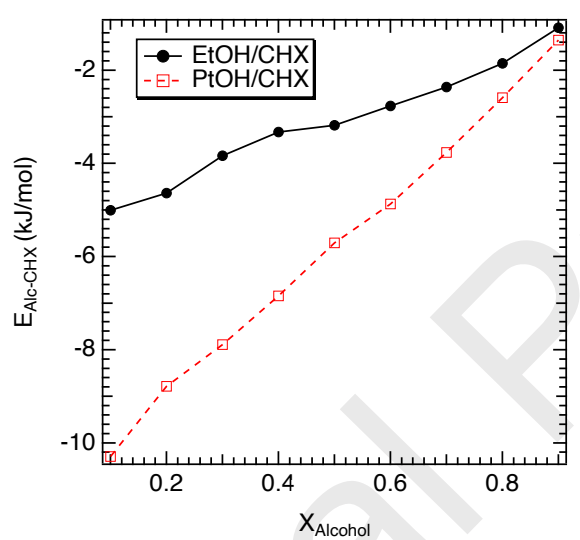

b)

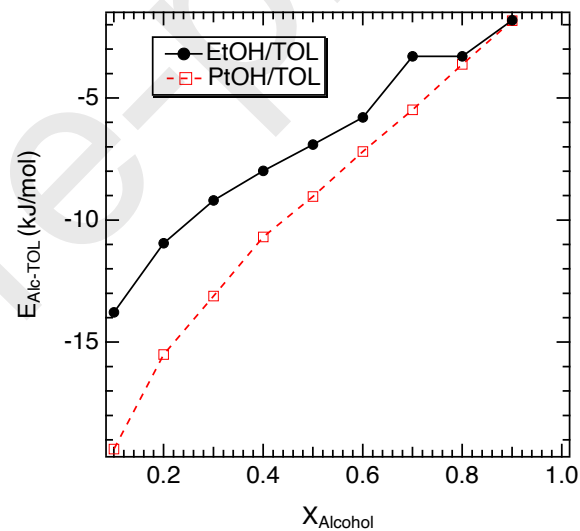

Figure 6. Calculated energy between the alkyl chain of alcohol molecules and CHX a) and TOL b) as a function of the molar fraction of alcohol.

\section{References}

[1] J. Kim, K. Lee, S. Kim, Pervaporation separation of water from ethanol through polymide composite membranes, J. Membr. Sci. 169 (2000) 81 .

[2] N. Hilmioglu, Bioethanol recovery using the pervaporation separation technique, Manage. Environ. Qual. 20 (2009) 165.

[3] Q. Kang, J. Huybrechts, B.-V. der Bruggen, J. Baeyens, T. Tan, R. Dewil, Hydrophilic membranes to replace molecular sieves in dewatering the bio-ethanol/water azeotropic mixture, Separation and Purification Technology 136 (2014) 144.

[4] I. Essafri, A. Ghoufi, Microstructure of nonideal methanol binary liquid mixtures, Phys. Rev. E 99 (2019) 062607. doi:10.1103/PhysRevE.99.062607.

[5] A. Ghoufi, Molecular origin of the prepeak in the structure factor of alcohols, J. Phys. Chem. B 124 (2020) 11501-11509.

[6] G. N. Swamy, G. Dharmaraju, G. K. Raman, Excess volumes of toluene mixtures with some alcohols at 303.15k, Canadian Journal of Chemistry 58 (3) (1980) 229-230. doi:10.1139/v80-037.

[7] C. B. Kretschmer, R. Wiebe, Thermodynamics of alcohol-hydrocarbon mixtures, The Journal of Chemical Physics 22 (10) (1954) 1697-1701. doi:10.1063/1.1739878.

[8] R. Thiyagarajan, L. Palaniappan, Molecular interaction study of two aliphatic alcohols with cyclohexane, CSIR (2008) 852-856.

[9] P. S. Nikam, B. S. Jagdale, A. B. Sawant, M. Hasan, Densities and viscosities of binary mixtures of toluene with methanol, ethanol, propan1-ol, butan-1-ol, pentan-1-ol, and 2-methylpropan-2-ol at (303.15, 308.15, 313.15) k, Journal of Chemical \& Engineering Data 45 (4) (2000) 559-563. doi:10.1021/je990317i.

[10] L. Hennous, A. A. Hamid, R. Lefort, D. Morineau, P. Malfreyt, A. Ghoufi, Crossover in structure and dynamics of a primary alcohol induced by hydrogen-bonds dilution, J. Chem. Phys. 141 (2014) 204503. 
[11] Požar, Lovrinčević, Zoranić, Primorać, Sokolić, F. A. Perera, Micro-heterogenity versus clustering in binary mixtures of ethanol with water or alkanes, Phys. Chem. Chem. Phys. 18 (2016) 23971.

[12] M. Mhanna, R. Lefort, L. Noirez, D. Morineau, Microstructure and concentration fluctuations in alcohol-toluene and alcohol-cyclohexane binary liquids: A small angle neutron scattering study, J. Mol. Liquids 218 (2016) 198.

[13] M. A. Tomza, P.; Czarnecki, Microheterogeneity in binary mixtures of propyl alcohols with water: Nir spectroscopic, two-dimensional correlation and multivariate curve resolution study, Journal of Molecular Liquids 209 (2015) 115 - 120. doi:https://doi.org/10.1016/j.molliq.2015.05.033.

[14] E. Vokacova, Z. S.; Pluharova, Understanding structure and dynamics of organic liquid mixtures by molecular simulations, Journal of Molecular Liquidsdoi:https://doi.org/10.1016/j.molliq.2019.04.055.

[15] H. C. Van Ness, J. Van Winkle, H. H. Richtol, H. B. Hollinger, Infrared spectra and the thermodynamics of alcohol-hydrocarbon systems, The Journal of Physical Chemistry 71 (5) (1967) 1483-1494. doi:10.1021/j100864a046.

[16] A. N. Fletcher, Effect of carbon tetrachloride upon the self-association of 1-octanol, The Journal of Physical Chemistry 73 (7) (1969) 22172225. doi: $10.1021 / \mathrm{j} 100727 \mathrm{a} 019$.

[17] R. Tanaka, S. Toyama, Excess molar volumes and excess molar heat capacities for binary mixtures of (ethanol + benzene, or toluene, or o-xylene, or chlorobenzene) at a temperature of $298.15 \mathrm{k}$, Journal of Chemical \& Engineering Data 42 (5) (1997) 871-874. doi:10.1021/je9700479.

[18] S. C. P. Hwa, W. T. Ziegler, Temperature dependence of excess thermodynamic properties of ethanol-methylcyclohexane and ethanol-toluene systems1, The Journal of Physical Chemistry 70 (8) (1966) 2572-2593. doi:10.1021/j100880a025.

[19] Z. S. L. Morávková, Z. Wagner, J. Line, Volumetric behaviour of binary and ternary liquid systems composed of ethanol, isooctane, and toluene at temperatures from (298.15 to 328.15)k. experimental data and correlation, The Journal of Chemical Thermodynamics 43 (12) (2011) 1906 - 1916. doi:https://doi.org/10.1016/j.jct.2011.06.021.

[20] S. S. Patil, S. R. Mirgane, B. R. Arbad, Excess molar volumes and deviation in viscosities of binary liquid mixtures of acrylic esters with hexane-1-ol at 303.15 and 313.15k, Journal of Saudi Chemical Society 18 (6) (2014) 945 - 952. doi:https://doi.org/10.1016/j.jscs.2011.11.018.

[21] B. Satheesh, D. Sreenu, T. S. Jyostna, Thermodynamic and spectroscopic studies of intermolecular interactions between isoamyl alcohol and monocyclic aromatic non-ideal binary liquid mixtures, Chemical Data Collections 28 (2020) 100448. doi:https://doi.org/10.1016/j.cdc.2020.100448

[22] D. Li, D. Xiao, X. Liu, J. Zhao, X. Xu, C. Wang, W. Wang, Densities and viscosities for the ternary system of (ethylcyclohexane + 1-butanol + ethyl octanoate) and corresponding binary systems at $\mathrm{t}=(293.15-323.15) \mathrm{k}$, The Journal of Chemical Thermodynamics 150 (2020) 106173. doi:https://doi.org/10.1016/j.jct.2020.106173.

[23] O. Hiroyuki, Excess volumes of (1-pentanol + cyclohexane or benzene) at temperatures between $283.15 \mathrm{k}$ and $328.15 \mathrm{k}$, The Journal of Chemical Thermodynamics 34 (6) (2002) 849-859. doi:10.1006/jcht.2001.0940.

[24] R. Baskaran, T. R. Kubendran, Density and excess molar volume in a binary mixture of o-anisaldehyde and chlorobenzene at 303.15, 313.15, and 323.15 k, Russian Journal of Physical Chemistry 83 (3) (2009) 350-352. doi:10.1134/S0036024409030054.

[25] W. L. Jorgensen, D. S. Maxwell, J. Tirado-Rives, Development and testing of the opls all-atom force field on conformational energetics and properties of organic liquids, Journal of the American Chemical Society 118 (45) (1996) 11225-11236. doi:10.1021/ja9621760.

[26] W. Smith, T. Forester, Dlpoly2.0: A general-purpose parallel molecular dynamics simulation package, Journal of Molecular Graphics 14 (3) (1996) 136 - 141. doi:https://doi.org/10.1016/S0263-7855(96)00043-4.

[27] M.-L. Tan, B. T. Miller, J. Te, J. R. Cendagorta, B. R. Brooks, T. Ichiye, Hydrophobic hydration and the anomalous partial molar volumes in ethanol-water mixtures, J. Chem. Phys. 142 (2015) 064501.

[28] S. Noskov, G. Lamoureux, B. Roux, Molecular dynamics study of hydration in ethanol-water mixtures using a polarizable force field, J. Phys. Chem. B 109 (2005) 6705.

[29] R. Baskaran, T. Kubendran, Density and excess molar volume in a binary mixture of o-anisaldehyde and chlorobenzene at 303.15, 313.15 , and 323.15 k, J. Phys. Chem. 83 (2009) 350.

[30] Y. Wang, G. A. Voth, Tail agrregation and domain diffusion in ionic liquids, J. Phys. Chem. B 110 (2006) 18601.

[31] S. Li, J. Bañuelos, P. Zhang, G. Feng, S. Dai, G. Rother, P. Cummings, Toward understanding the structural heterogeneity and ion pair stability in dicationic ionic liquids, Soft Matter 10 (2014) 9193.

[32] A. Luzar, D. Chandler, Structure and hydrogen bond dynamics of water-dimethyl sulfoxide mixtures by computer simulations, The Journal of Chemical Physics 98 (10) (1993) 8160-8173. doi:10.1063/1.464521.

[33] A. Ghoufi, I. Hureau, R. lefort, D. Morineau, Hdrogen-bond-induced supermolecular assemblies in a nanoconfined tertiary alcohol, J. Phys. Chem. C 115 (2011) 36.

[34] A. Ghoufi, I. Hureau, D. Morineau, R. Renou, A. Szymczyk, Confinement of tert-butanol nanoclusters in hydrophilic and hydrophobic silica nanopores, J. Phys. Chem. C 117 (2013) 15203.

[35] A. Ghoufi, F. Artzner, P. Malfreyt, Physical properties and hydrogen-bonding network of water-ethanol mixtures from molecular dynamics simulations, The Journal of Physical Chemistry B 120 (4) (2016) 793-802. doi:10.1021/acs.jpcb.5b11776.

[36] R. Mhanna, R. Lefort, L. Noirez, D. Morineau, Microstructure and concentration fluctuations in alcohol-toluene and alcoholcyclohexane binary liquids: A small angle neutron scattering study, Journal of Molecular Liquids 218 (2016) 198 - 207. doi:https://doi.org/10.1016/j.molliq.2016.02.070. 

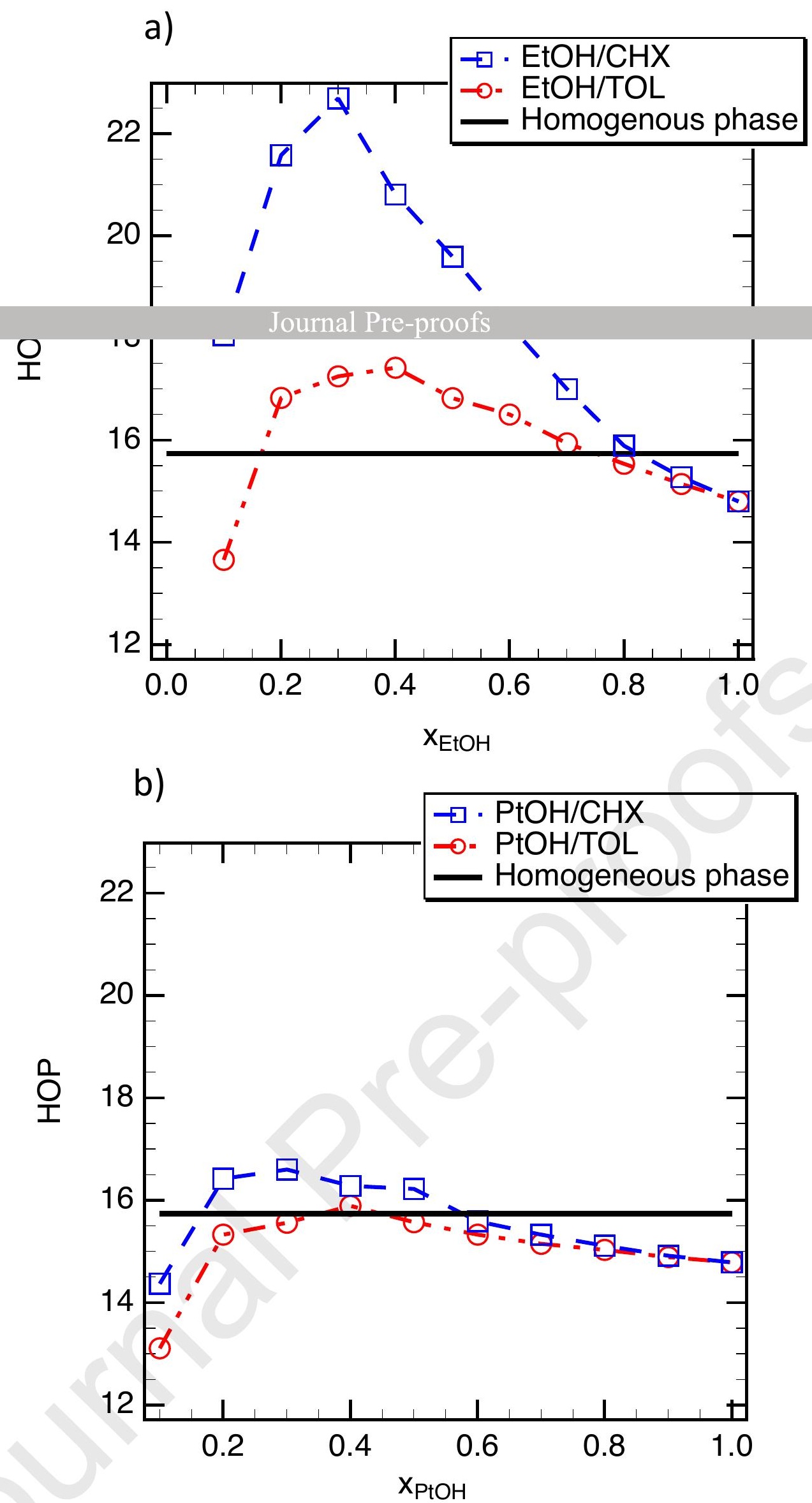

c)

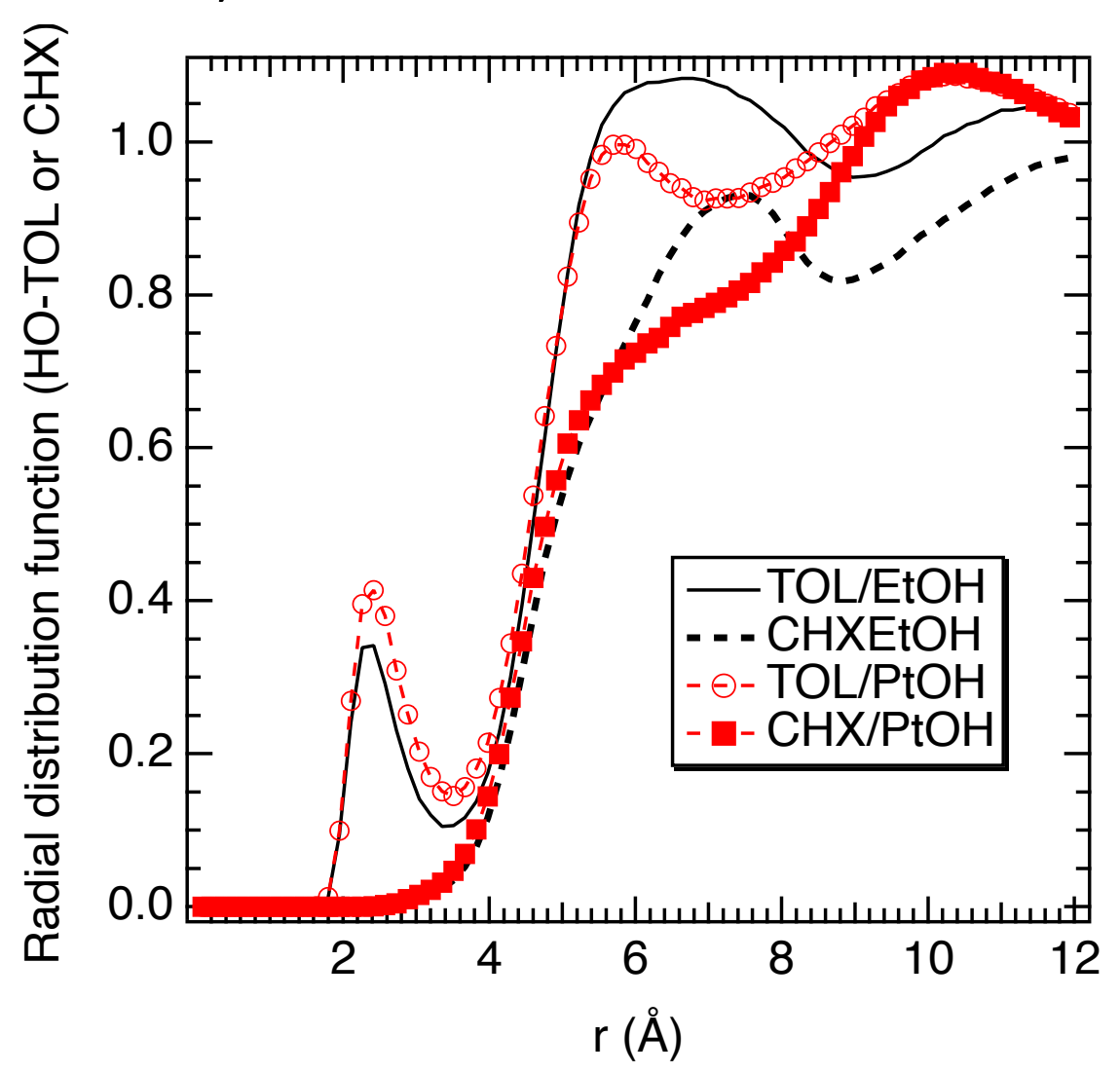


a)
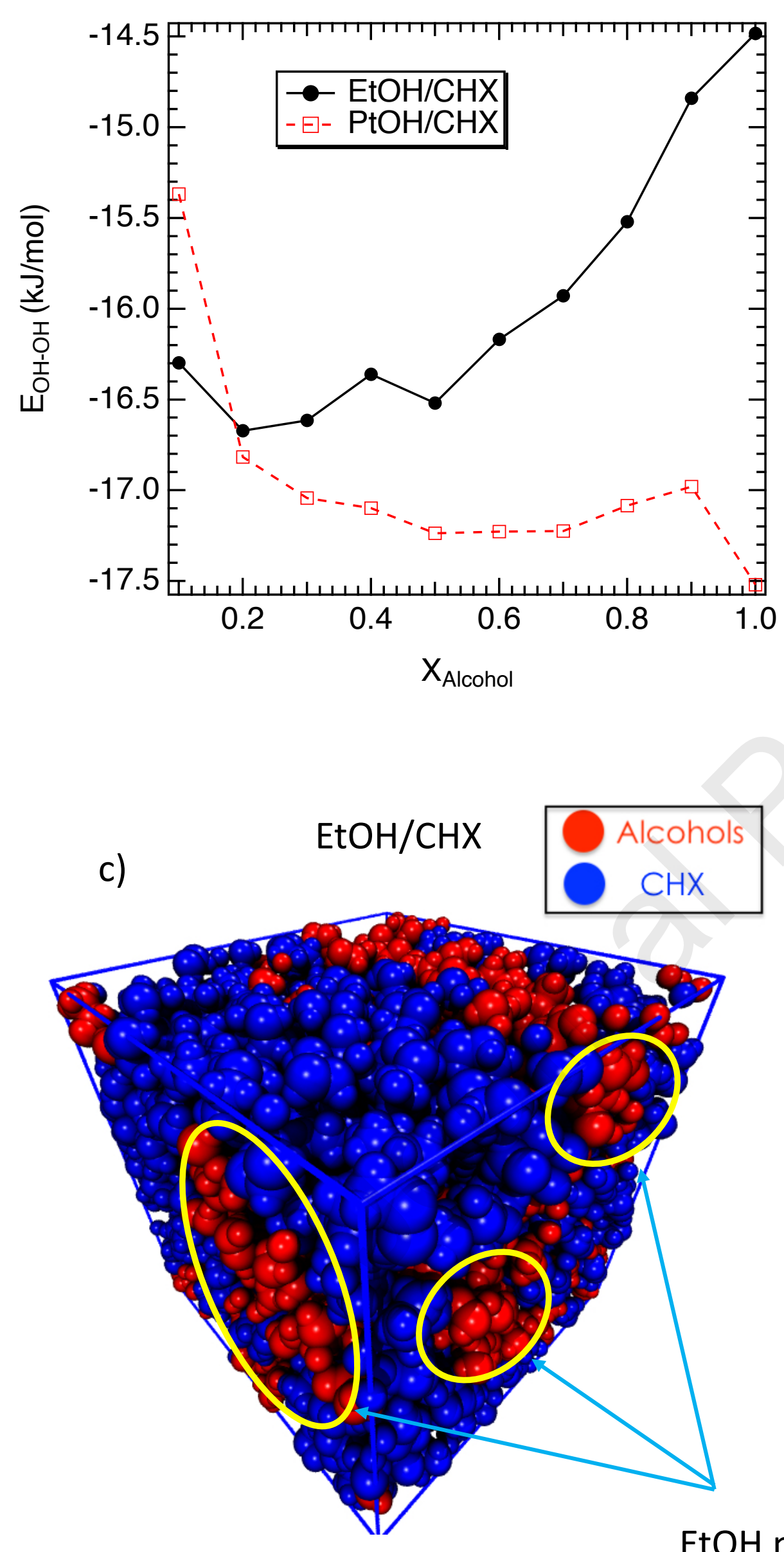

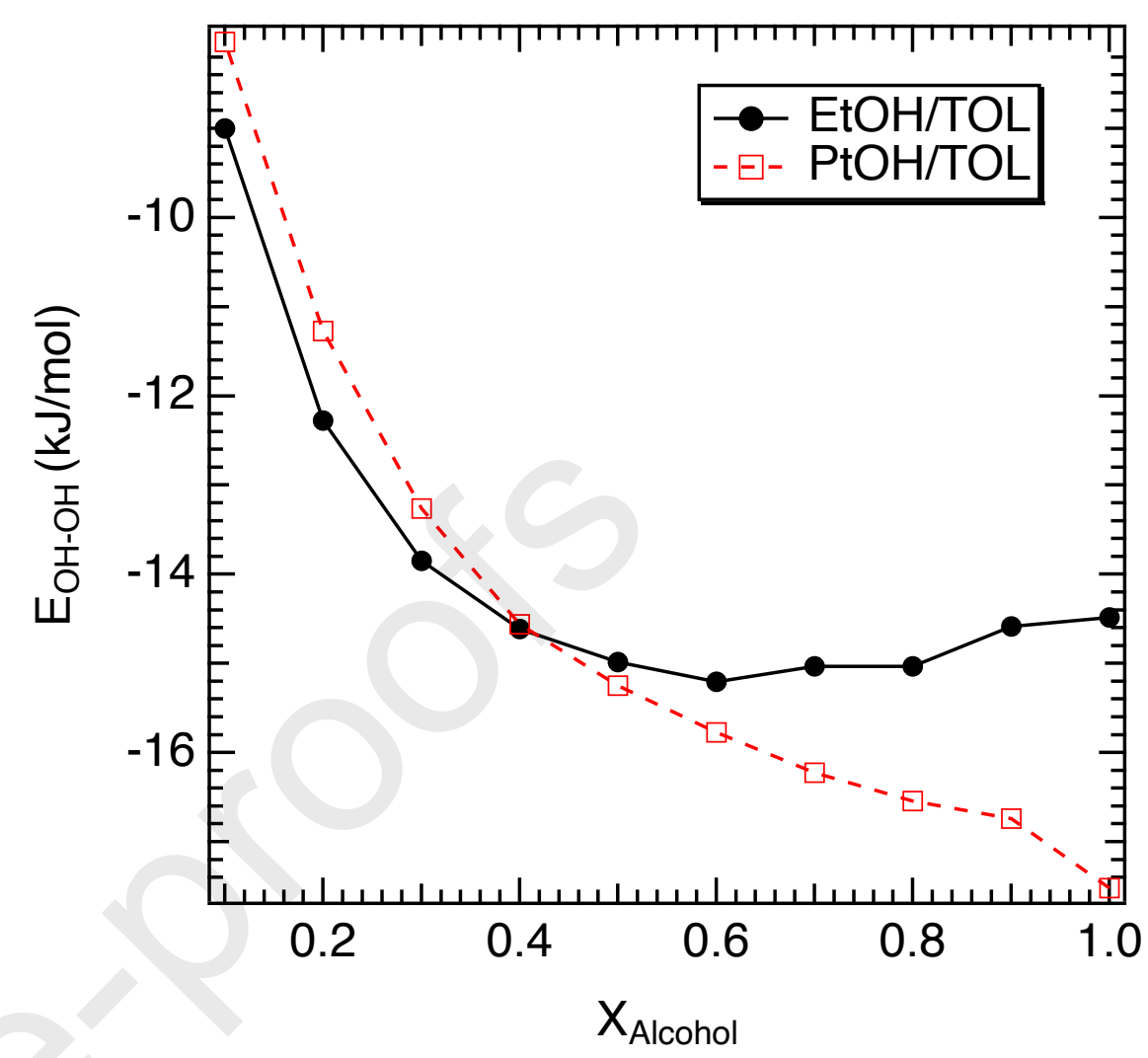

$\mathrm{PtOH} / \mathrm{CHX}$

d)

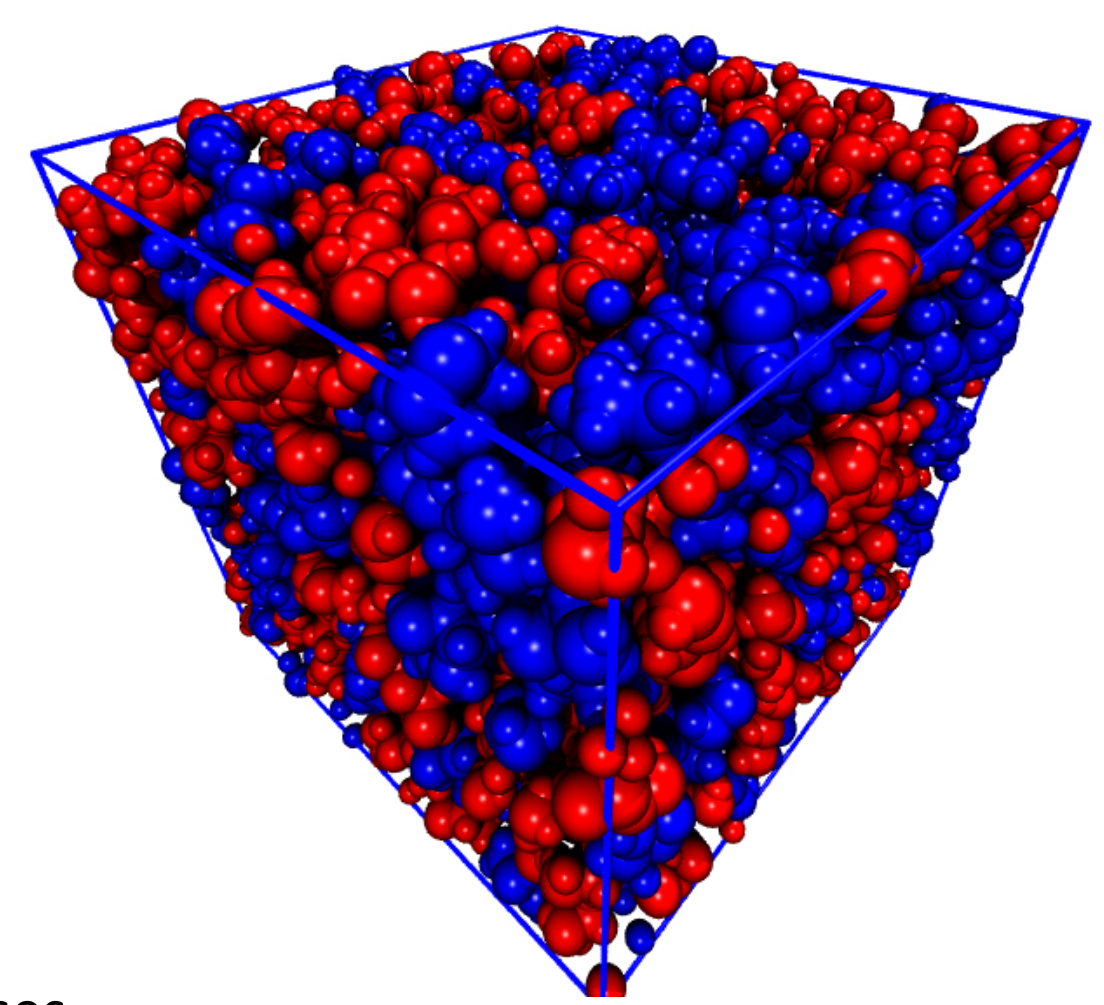


a)
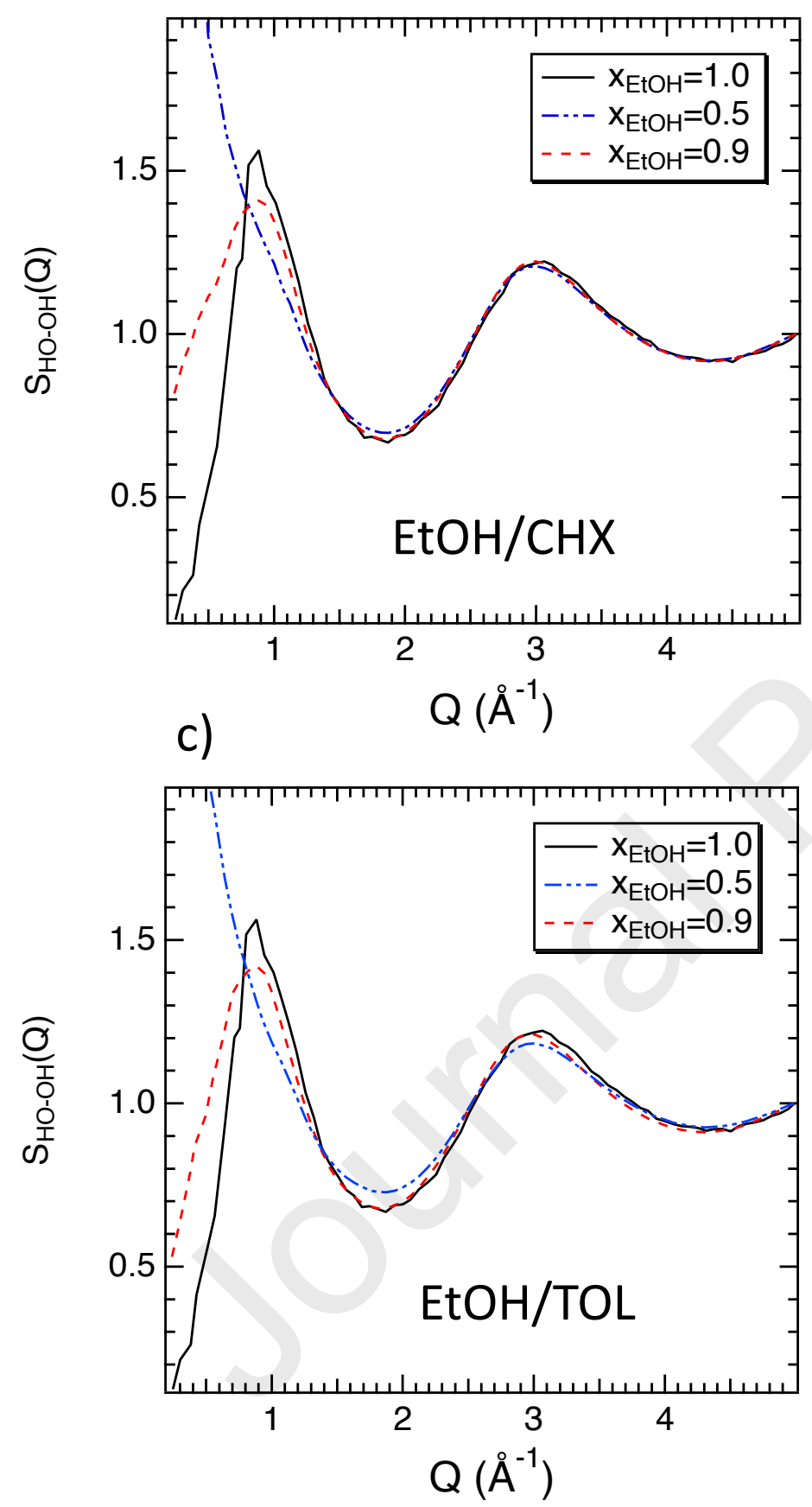

b)
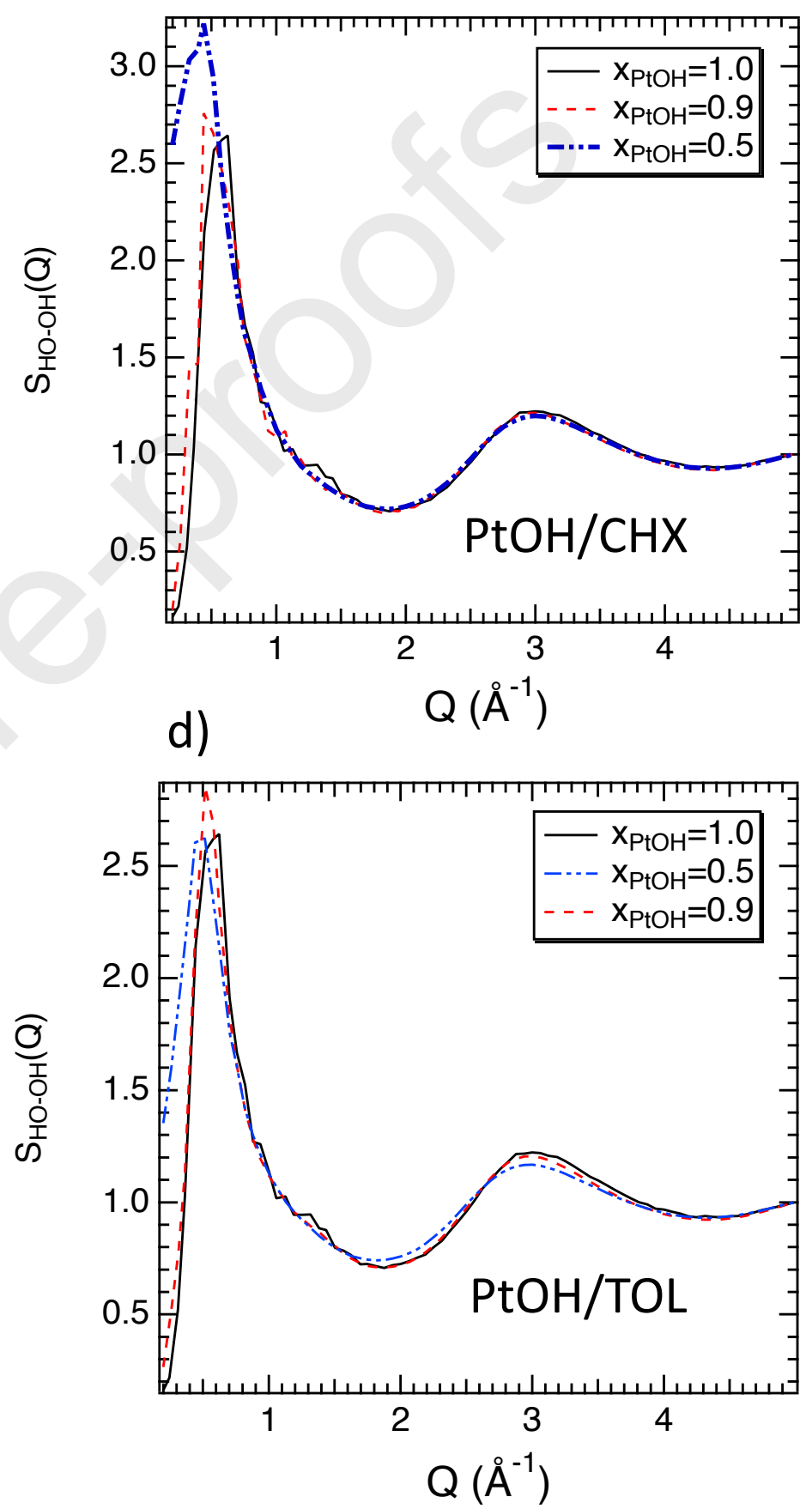
a)

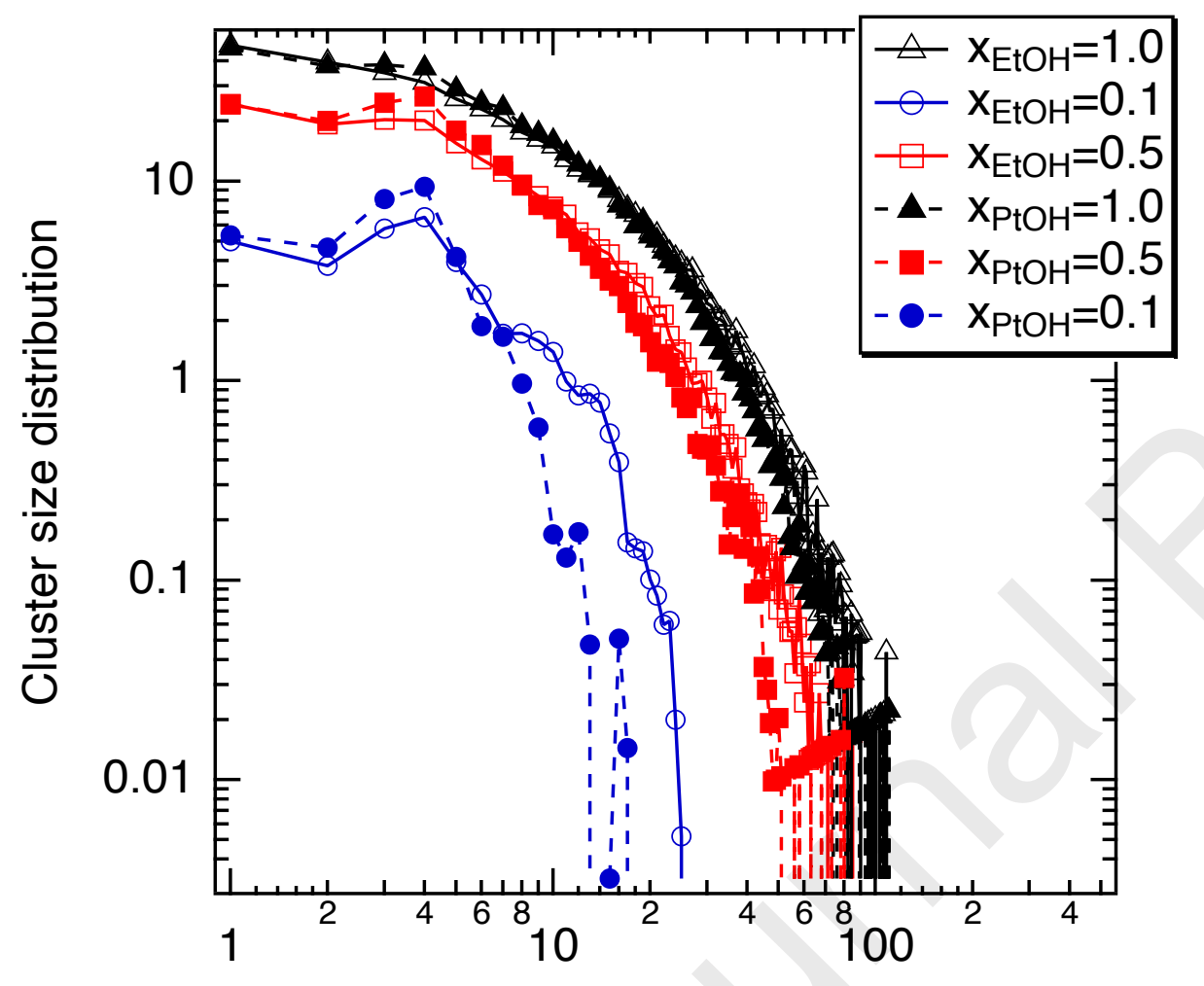

Cluster size

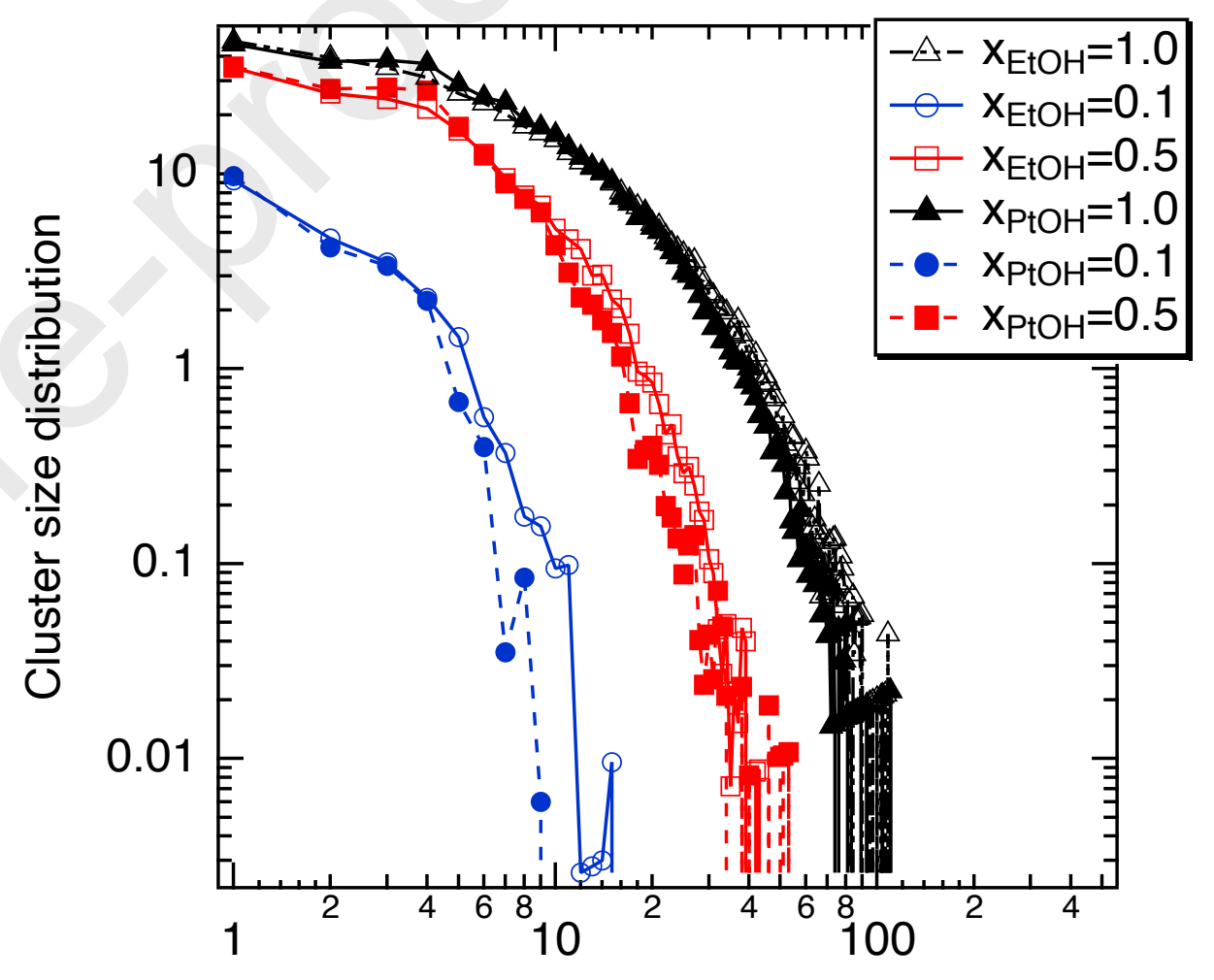

Cluster size 
a)

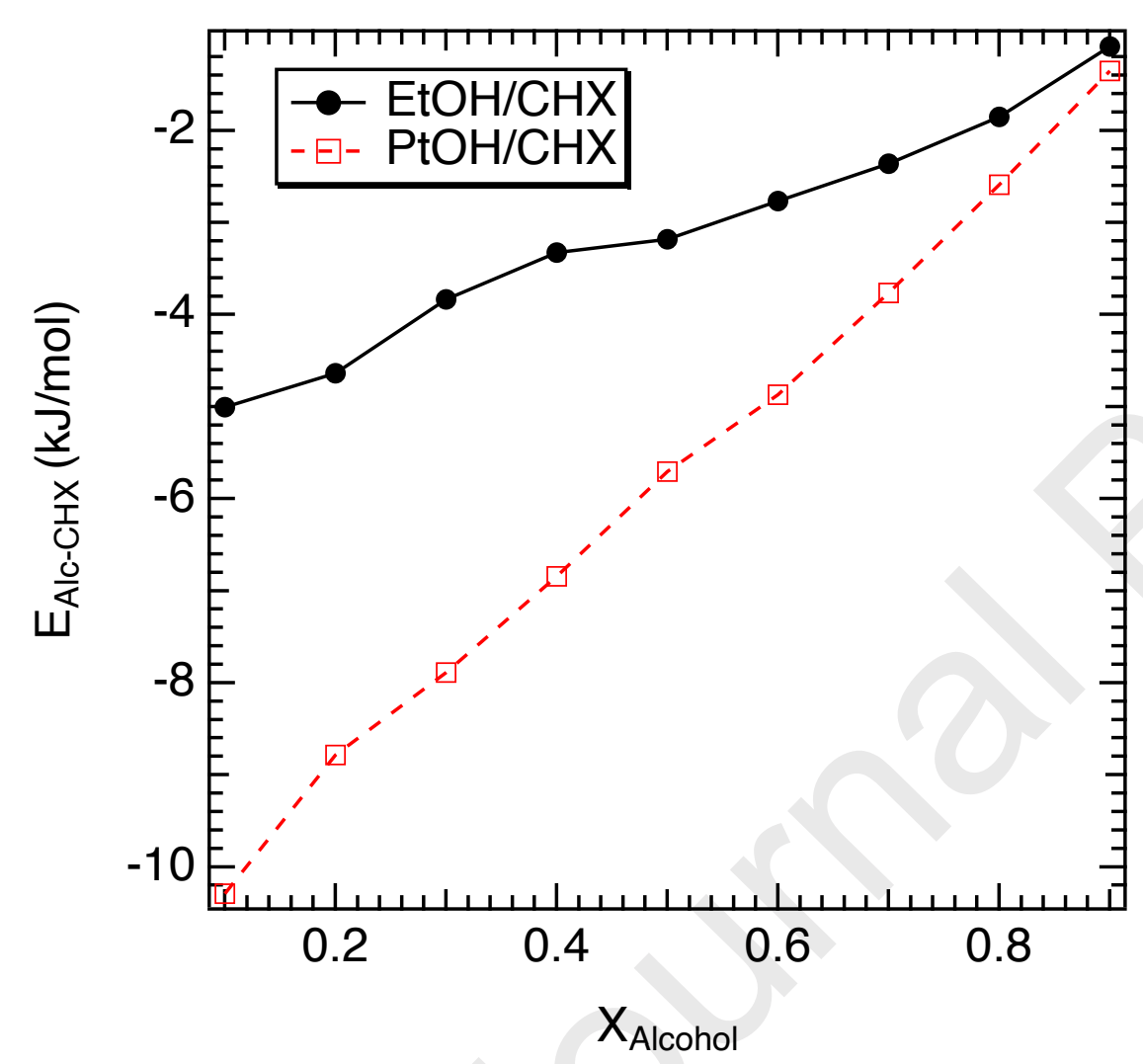

b)

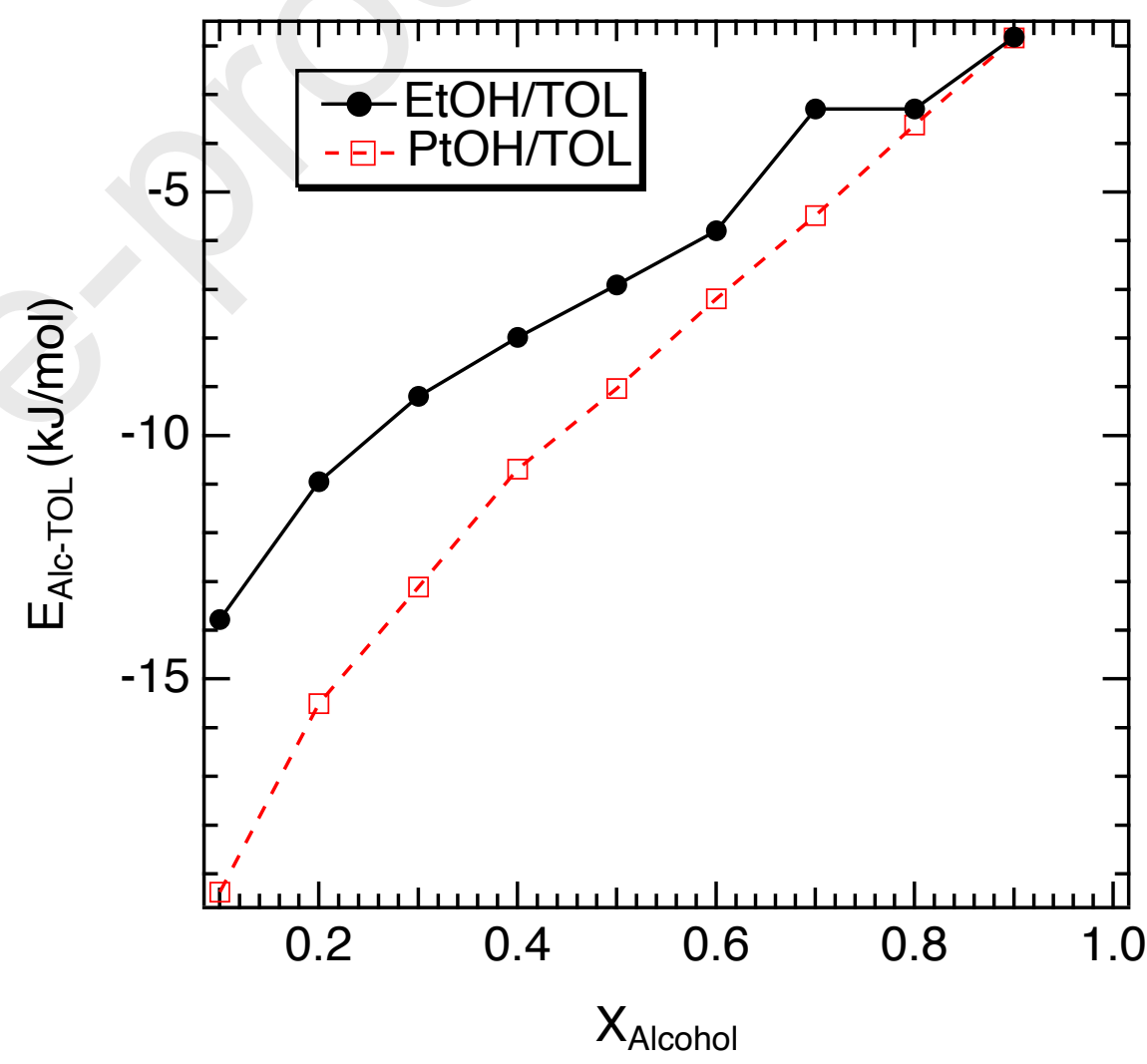




\section{Declaration of interests}

$\bigotimes$ The authors declare that they have no known competing financial interests or personal relationships that could have appeared to influence the work reported in this paper.

$\square$ The authors declare the following financial interests/personal relationships which may be considered as potential competing interests: 
Aziz Ghoufi: Conceptualization, Methodology, Simulation, Supervision, Writing- Reviewing and Editing Ilham Essafri.: Simulation, Writing- Original draft preparation, Visualization 